Review Article

\title{
HIV Prevalence Trends, Risky Behaviours, and Governmental and Community Responses to the Epidemic among Men Who Have Sex with Men in China
}

\author{
Eric P. F. Chow, ${ }^{1,2,3,4}$ Joseph T. F. Lau, ${ }^{5}$ Xun Zhuang, ${ }^{6}$ Xiaohu Zhang, ${ }^{7,8}$ \\ Yanjie Wang, ${ }^{1}$ and Lei Zhang ${ }^{1,4}$ \\ ${ }^{1}$ The Kirby Institute, Faculty of Medicine, University of New South Wales, Sydney, NSW 2052, Australia \\ ${ }^{2}$ Central Clinical School, Faculty of Medicine, Nursing and Health Sciences, Monash University, Melbourne, VIC 3800, Australia \\ ${ }^{3}$ Melbourne Sexual Health Centre, Alfred Health, Carlton, VIC 3053, Australia \\ ${ }^{4}$ Comprehensive AIDS Research Center, School of Medicine, Tsinghua University, Beijing 100084, China \\ ${ }^{5}$ Centre for Health Behaviors Research, School of Public Health and Primary Care, Faculty of Medicine, \\ The Chinese University of Hong Kong, Hong Kong Special Administrative Region, China \\ ${ }^{6}$ School of Public Health, Nantong University, Nantong, Jiangsu 226019, China \\ ${ }^{7}$ Department of Sociology, Tsinghua University, Beijing 100084, China \\ ${ }^{8}$ China Food and Drug Administration Institute of Executive Development, Beijing 100073, China
}

Correspondence should be addressed to Xun Zhuang; ntzhuang@163.com and Lei Zhang; lzhang@kirby.unsw.edu.au

Received 26 September 2013; Revised 6 December 2013; Accepted 3 January 2014; Published 14 April 2014

Academic Editor: Yujiang Jia

Copyright (C) 2014 Eric P. F. Chow et al. This is an open access article distributed under the Creative Commons Attribution License, which permits unrestricted use, distribution, and reproduction in any medium, provided the original work is properly cited.

\begin{abstract}
Purpose of Review. Numerous studies reported the rapid spread of HIV/AIDS epidemic among men who have sex with men (MSM) in China. This paper aims to investigate the overall epidemic trend and associated high-risk behaviours among Chinese MSM and to explore the governmental and community responses to the epidemic. Recent Findings. HIV prevalence among Chinese MSM increased rapidly in all Chinese regions in the past decade and disproportionally affected the Southwest China. In addition to the high-risk homosexual behaviours, overlapping bisexual, commercial, and drug use behaviours are commonly observed among Chinese MSM. The Chinese government has significantly expanded the surveillance efforts among MSM over the past decade. Community responses against HIV have been substantially strengthened with the support of international aid. However, lack of enabling legal and financial environment undermines the role of community-based organisations (CBOs) in HIV surveillance and prevention. Conclusion. HIV continues to spread rapidly among MSM in China. The hidden nature of MSM and the overlapping homosexual, bisexual, and commercial behaviours remain a challenge for HIV prevention among MSM. Strong collaboration between the government and CBOs and innovative intervention approaches are essential for effective HIV surveillance and prevention among MSM in China.
\end{abstract}

\section{HIV Epidemic in China}

Estimated 780,000 people in China are currently living with HIV/AIDS, accounting for $0.057 \%$ of the Chinese population in 2011 [1]. HIV epidemic was initiated and mainly transmitted by sharing injecting equipment among injecting drug users (IDU) in China in the past decade [2, 3]. However, sexual transmission, especially male-to-male homosexual transmission, has become the major mode of
HIV transmission in recent years $[4,5]$. The latest national report revealed that the proportion of newly diagnosed HIV cases due to male homosexual contact has increased from $12.2 \%$ in 2007 to $32.5 \%$ in 2009 [5]; while the national HIV prevalence among MSM had a 4.5 -fold increase in the past ten years (i.e., from $1.4 \%$ in 2001 to $6.3 \%$ in 2011) $[1,6]$. The level of HIV prevalence in MSM is still relatively low compared to other Asian countries such as Cambodia (7.8\%), Indonesia (9.0\%), and Thailand (24.6\%) [7]. Currently, Chinese MSM 
represents about $2-4 \%$ of the sexually-active male population in China (i.e., 5-10 million) $[8,9]$.

The rapid spread of HIV epidemic among Chinese MSM has become a national concern [10]. Several published review articles on Chinese MSM have described the HIV disease burden and its transmission through high-risk sexual behaviours among MSM in China [11-13]. Extended from previous findings, this paper aims to (1) describe the trend of HIV epidemic among MSM in relation to the less investigated overlapping risk behaviours and (2) assess the current health polices and surveillance efforts from the Chinese government and community responses to the epidemic. Assessing these specific aspects provides insightful implications for the country's public health responses and informs relevant health policies.

\section{Rapid Transmission of HIV among Chinese MSM}

Growing trends of HIV epidemic among MSM have been observed in all Chinese provinces, municipalities, and autonomous regions; however, the epidemic varies geographically and temporally (Figure $1(\mathrm{a})$ ). The national HIV prevalence has increased rapidly from $0.9 \%$ in 2003 to $6.3 \%$ in 2011 [14]. Several studies have also indicated that MSM recruited from gay venues (i.e., gay bars, saunas, and bathhouses) have a higher HIV prevalence compared with those MSM recruited from the Internet, clinics, or other settings [1517]. Furthermore, HIV incidence have also increased in several municipalities and provinces (Figure 1(b)), such as Beijing Municipality (from 2.9 to 8.1 per 100 person-years during 2005-2010), Chongqing Municipality (from 8.0 to 15.4 per 100 person-years during 2006-2009), Liaoning Province (from 5.1 to 10.2 per 100 person-years during 2007-2009), Jiangsu Province (from 5.7 to 8.2 per 100 person-years during 2008-2011), and Zhejiang Province (from 3.5 to 6.3 per 100 person-years during 2010-2012). Provinces in the Southwest and Northwest regions consistently exhibit higher prevalence levels than other parts of China. Previous study showed that the proportion of all reported diagnosed cases that were attributed to male homosexual exposure in the city of Kunming of Southwest China has increased from $2.2 \%$ in 2000 to $42.2 \%$ in 2007 [18].

\section{High-Risk Homosexual Behaviours}

Approximately $85 \%$ and $90 \%$ of MSM have had anal sex and oral sex with men in the past six months, respectively $[19,20]$, and each Chinese MSM has approximately $7.2 \pm$ 17.3 oral sex partners and $6.6 \pm 15.6$ anal sex partners [20]. Correct and consistent use of condoms can prevent HIV transmission by $85-90 \%$ [21-25]; however, condom usage varies across types of sexual partnerships among Chinese MSM. A recent systematic review and meta-analysis have demonstrated that regular male partnerships in Chinese MSM have the lowest consistent condom use during anal intercourse over the past six months (19.9\%) compared with noncommercial casual (30.4\%) and commercial partnerships
(58.0\%) [26]. Low condom use is mainly due to the preference of better sexual sensation and the fear of making partners feeling untrusted. Since most of the MSM perceive oral sex as a "safe-sex" activity [27], the rate of condom use in oral sex is extremely low $(\sim 10 \%)[20,28]$. Apart from these, a substantial proportion of MSM also have participated in other sexual contacts such as rimming (26.0\%) and fisting (27.6\%) [20]. About 27.7\% have reported experiencing bleeding during or after intercourse [20]. Although these unusual sexual practices are considered as low risk sexual activities, the exchange of body fluids (i.e. blood and semen) could possibly facilitate HIV transmission [29]. In addition, nonmonogamous relationships are common among Chinese MSM [14, 30, 31]. National behavioural surveillance reported that the proportion of MSM who had multiple male sex partners in the past six months increased from $68.0 \%$ in 2008 to $85.4 \%$ in 2011 [14], and about $18.6 \%$ have participated in group sex activities in the past 12 months [20].

\section{Prevalent Overlapping Risk Behaviours}

4.1. Bisexual Behaviours. "Of the three kinds of unfilial conducts, having no posterity to continue the family line is the gravest" is one of the traditional family values in China [32]. Chinese parents expect children to marry and have children to continue the family line $[33,34]$. Previous studies have reported that 25-35\% of Chinese MSM are currently married to a female [35-37] and over 70\% of MSM will potentially enter a heterosexual marriage during their lifetime due to social and family pressure [38-40]. Married MSM often have unprotected sex with their wives not only for the reason of reproduction [41], but also an indication of husbands' fidelity to their wives [42]. It has been reported that the rate of consistent condom use between MSM and female partners in the past six months is only $23.3 \%(95 \%$ CI: $11.3-42.1 \%$ ) [12]. Moreover, a systematic review and metaanalysis estimated that about $68.0 \%$ of the HIV-positive Chinese MSM have unprotected vaginal intercourse (UVI) with their female partners [43]. Given that MSM who have sex with women is 1.3 (95\% CI: 1.0-1.6) times higher risk of HIV compared to MSM who have sex with men only; female partners of bisexual MSM are at higher risk of HIV [44]. A recent study estimated that the HIV incidence among female partners of bisexual MSM has significantly increased 5.3 fold from 0.18 per 1000 person-years in 2002 to 0.88 per 1000 person-years in 2010 in China [45]. Bisexual behaviours of MSM pose potential threats of bridging HIV transmission to their female partners, spreading the epidemic into the general female population [46]. Disclosure of homosexuality is not common and only $11 \%$ of married Chinese MSM have disclosed their homosexuality to their wives [39]. Sexual harassment is common between homosexual men and their female partners, and $30 \%$ of wives have reported experiencing domestic violence by their homosexual or bisexual husbands [47].

4.2. Commercial Sexual Activities. Available studies have suggested that substantial proportion of Chinese MSM is also involved in the male-to-male commercial sex trade. 


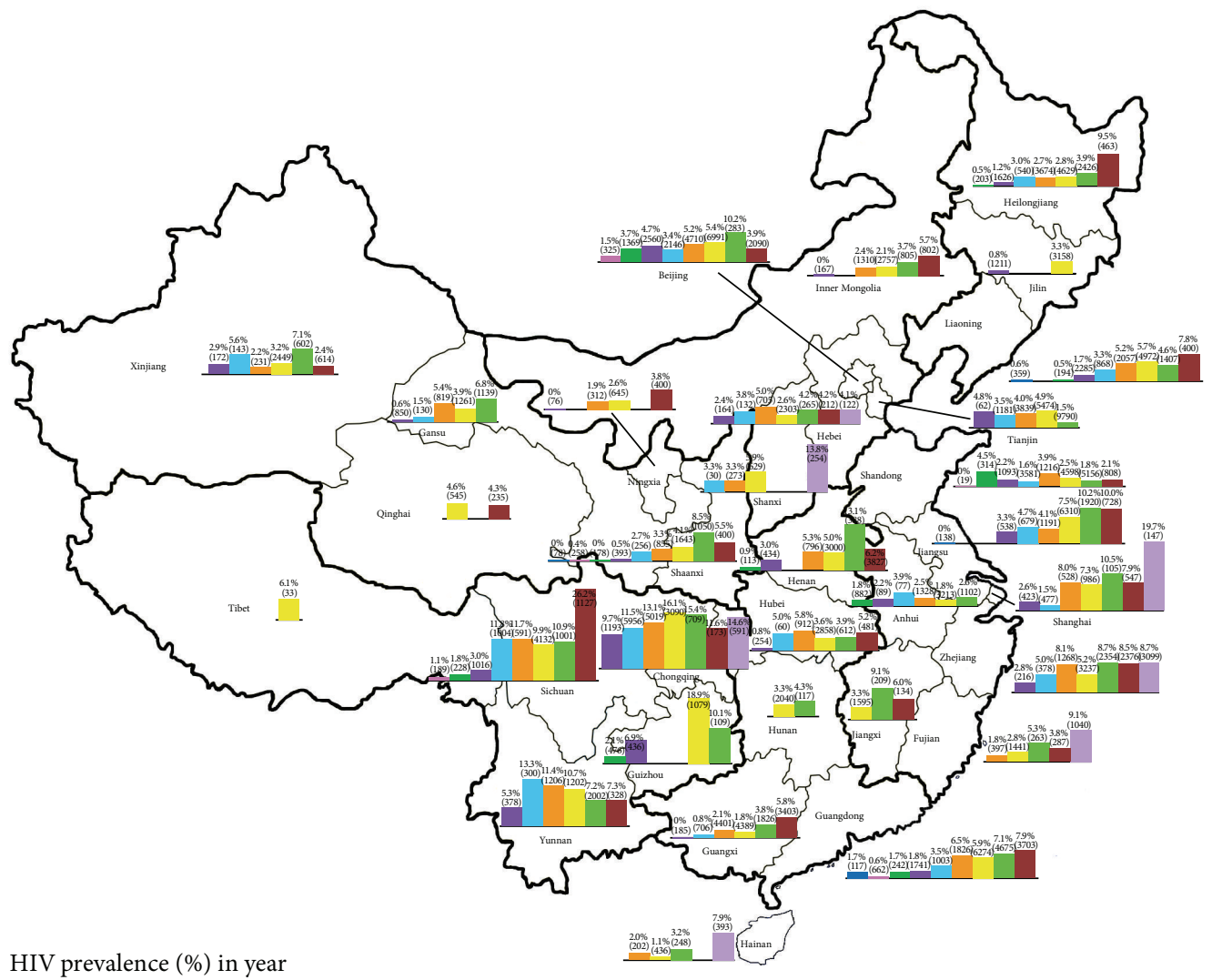

HIV prevalence (\%) in year

- 2003 - $2004-2005$ - $2006-2007$

- $2008-2009-2010-2011-2012$

(a)

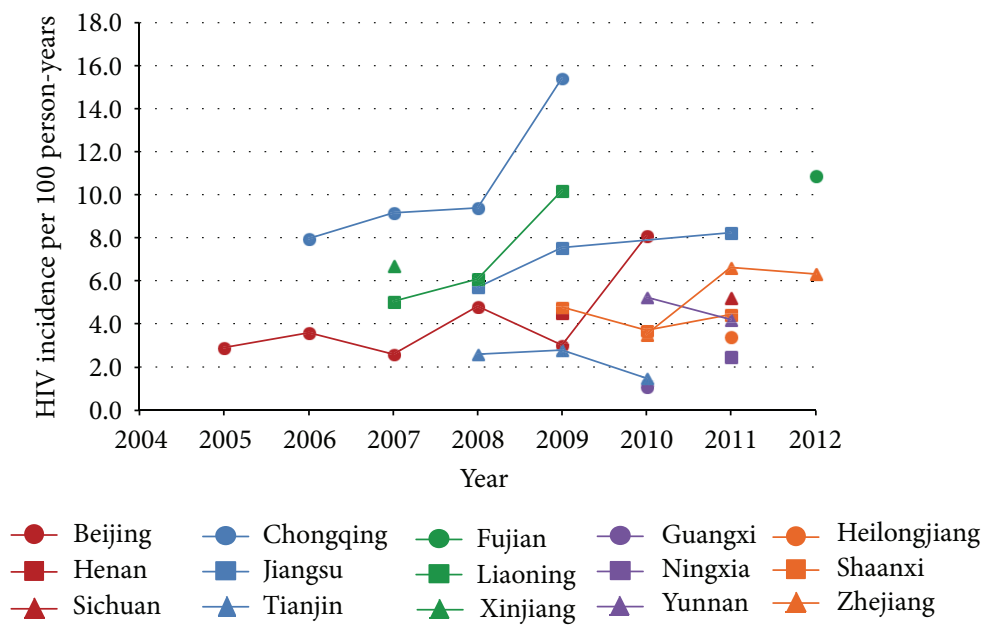

(b)

FiguRe 1: (a) HIV prevalence among MSM in China (2003-2012). HIV prevalence in Anhui [48-57]; Beijing [48, 58-81]; Chongqing [20, 35, 36, 48, 82-92]; Fujian [48, 93-98]; Gansu [36, 48, 99-101]; Guangdong [17, 46, 48, 52, 102-124]; Guangxi [48, 125-138]; Guizhou [48, 139144]; Hainan [48, 68, 145-147]; Hebei [48, 148-157]; Heilongjiang [20, 48, 54, 69, 76, 77, 100, 158-166]; Henan [20, 48, 54, 69, 76, 77, 167-174]; Hubei [20, 48, 63, 175-179]; Hunan [48, 180-182]; Inner Mongolia [48, 100, 183-187]; Jiangsu [20, 48, 68, 188-206]; Jiangxi [48, 207-210]; Jilin [48, 100]; Liaoning [20, 48, 55, 68, 100, 163, 211-223]; Ningxia [48, 100, 224, 225]; Qinghai [226, 227]; Shaanxi [20, 48, 68, 228-231]; Shandong [48, 68, 180, 232-247]; Shanghai [20, 48, 68, 248-252]; Shanxi [48, 253-255]; Sichuan [20, 48, 69, 76, 77, 123, 256-268]; Tianjin [48, 68, 269274]; Tibet [48, 275]; Xinjiang [48, 276-281]; Yunnan [48, 68, 168, 282-290]; and Zhejiang [48, 68, 291-303]. The percentages on the bar chart represent the prevalence of HIV infection among MSM and the numbers in the round bracket represent the total number of MSM screened; (b) HIV incidence among MSM in China (2005-2012). HIV incidence in Beijing [64, 70, 74, 304, 305]; Chongqing [306-308]; Fujian [98]; Guangxi [309]; Heilongjiang [310]; Henan [311]; Jiangsu [190, 312-316]; Liaoning [55, 216]; Ningxia [317]; Shaanxi [230, 318]; Sichuan [319]; Tianjin [272, 274]; Xinjiang [279]; Yunnan [289, 320]; and Zhejiang [299, 321]. 
Approximately $6.5-22.6 \%$ of the Chinese MSM have paid for sex with men $[58,232,322,323]$; on the other hand, about $4.9-24.3 \%$ have sold sex to men in the past six months [58, 322-326]. In addition, male sex workers are coined as "money boys" or informally as " $y \bar{a} z \grave{\imath}$ " (duck; who serves male and female clients) and "é" (goose; who serves male clients only) in the Chinese context [327]. Money boys have borne a disproportionate burden of HIV infection [11, 328-331]; however, very little epidemiological and sociobehavioural studies focus on this subpopulation. Previous studies have shown that money boys are usually younger, less educated, and more likely to have unprotected sex with multiple male clients compared to the broader MSM population [11, 328330]. A survey has reported that about $13.2 \%$ of MSM are engaged in paid sex activity but only $59.7 \%$ have used condom at every anal sex over the past six months. Additionally, nearly half (i.e., 43.1\%) of the money boys also have a heterosexual partnership but only $36.0 \%$ use condom with their female partners over the past six months [329]. Most of the money boys often move between cities for sex trade in order to avoid being recognised by the local community $[11,19,328]$, such domestic migration potentially facilitates the transmission of HIV across geographical locations [332334]. Recent review demonstrated that the odds of exposure to HIV among money boys are 1.3 (95\% CI: 1.1-1.5) times higher than the odds of exposure to HIV among the broader MSM population [11].

4.3. Injecting Behaviours. It is shown that about $8 \%$ of MSM who also have injected drugs in the past 12 months [20]. China has a long history of illicit drug trafficking and high rates of HIV infection among IDU $[2,3,335]$. Recent national report revealed that six out of the 31 Chinese provinces (i.e., Yunnan, Xinjiang, Guangdong, Guangxi, Sichuan, and Guizhou) accounted for $84.2 \%$ of the HIV epidemic among the IDU population [336]. At the same time, MSM in these provinces also have the highest HIV prevalence across the country (Figure 1(a)). The overlapping risk behaviours among MSM who also inject drugs (MSM-IDU) are likely to facilitate HIV transmission [337, 338]. Currently, the injecting and needle-sharing behaviour among MSM in China is little known. It remains a challenge to promote public health interventions to this overlapping population [339].

\section{Governmental Responses to HIV among Chinese MSM}

Male-to-male sexual activity is no longer punishable by law in China [340, 341]. The Chinese supreme court has ruled to exclude sodomy as a criminal act in 1957 [102]. The Chinese government abolished the "Hooliganism Law" from the Chinese Criminal Code in 1997 [342, 343], which signifies the decriminalisation of homosexuality in China. Furthermore, the term "homosexuality" was also removed from the list of psychiatric disorders by the Chinese National Psychiatric Association in 2001 [344]. With the increasingly permissible legal environment, the first HIV sentinel surveillance (HSS) site to target MSM was established in Heilongjiang Province in 2002 [345]. Two additional HSS sites for MSM were established in Anhui and Henan Provinces in 2005 [345]. The number of HSS sites further increased to 17 in 2009, covering eleven Chinese provinces [346]. Since then, there was a dramatic 6-fold increase in the number of HSS sites during 20092011 [347]. Currently, China hosts 108 HSS sites, monitoring HIV transmission and risk behaviours among MSM in all 31 Chinese provinces except the Tibet Autonomous Region (Figure 2) [14]. Routine epidemiological and behavioural information are collected in annual cross-sectional surveys $[348,349]$. Participants are recruited through various methods, including snowball, venue-based, and internet recruitment sampling methods [14, 347]. Despite of this large scaleup of surveillance efforts, the current surveillance coverage remains insufficient to capture the trend of HIV and sexually transmitted infections (STIs) among MSM in many parts of the country $[347,350]$. Recently, the central government funding for the HIV/AIDS responses has significantly scaled up from RMB 1.1 billion ( US\$ 154.2 million) in 2008 [5] to RMB 3.4 billion ( US\$ 497.3 million) in 2010 [351]. However, only US\$ 4.4 million in 2008 and US\$ 12.7 million in 2010 were set aside for MSM, accounting for only 2-3\% of the total funding [148].

HIV testing service is a key component of HIV surveillance $[352,353]$. Despite a significant increasing trend of $\mathrm{HIV}$ annual testing rate among MSM (from 11.0\% in 2003 to $50.4 \%$ in 2011 ) [11], approximately $61.1-87.0 \%$ of HIVinfected MSM remain undiagnosed [18, 354]. The low HIV testing rate among Chinese MSM is associated with a number of psychological and structural barriers. The majority of MSM perceive themselves as healthy and with low risk of acquiring HIV [31, 355]. Double social stigma against gay men and HIV patients in China complicate MSM to disclose their sexual orientation and/or HIV positive status [20, 355, 356]. The Chinese Stigma Index Report revealed that $25 \%$ of Chinese medical staff had negative and discriminatory attitudes towards people living with HIV (PLHIV) in 2009 [357]. Lacking of trust obstructs the uptake of HIV testing and subsequent medical procedures among MSM [31, 358, 359]. Unawareness of HIV serostatus among HIV-infected MSM may continue to fuel the spread of the virus [358]. In terms of structural barriers, a large proportion of MSM are not aware of the locations of any HIV testing site in their neighbourhood $[20,355,356]$, likely due to the lack of outreach of HIV intervention programs for MSM. However, successful roll-out of any of these interventions' programs relies on their ability to protect the identity and privacy of MSM. Due to the anonymous nature of the Internet, a study revealed that the majority of Chinese MSM (84.7\%) would prefer receiving HIV/AIDS-related intervention via Internet, instead of receiving the information from the China Centers for Disease Control and Prevention (CDC) (28.4\%) and hospitals (22.8\%) [360]. This shows that the non-face-to-face Internet-based intervention is a more acceptable approach to Chinese MSM. 


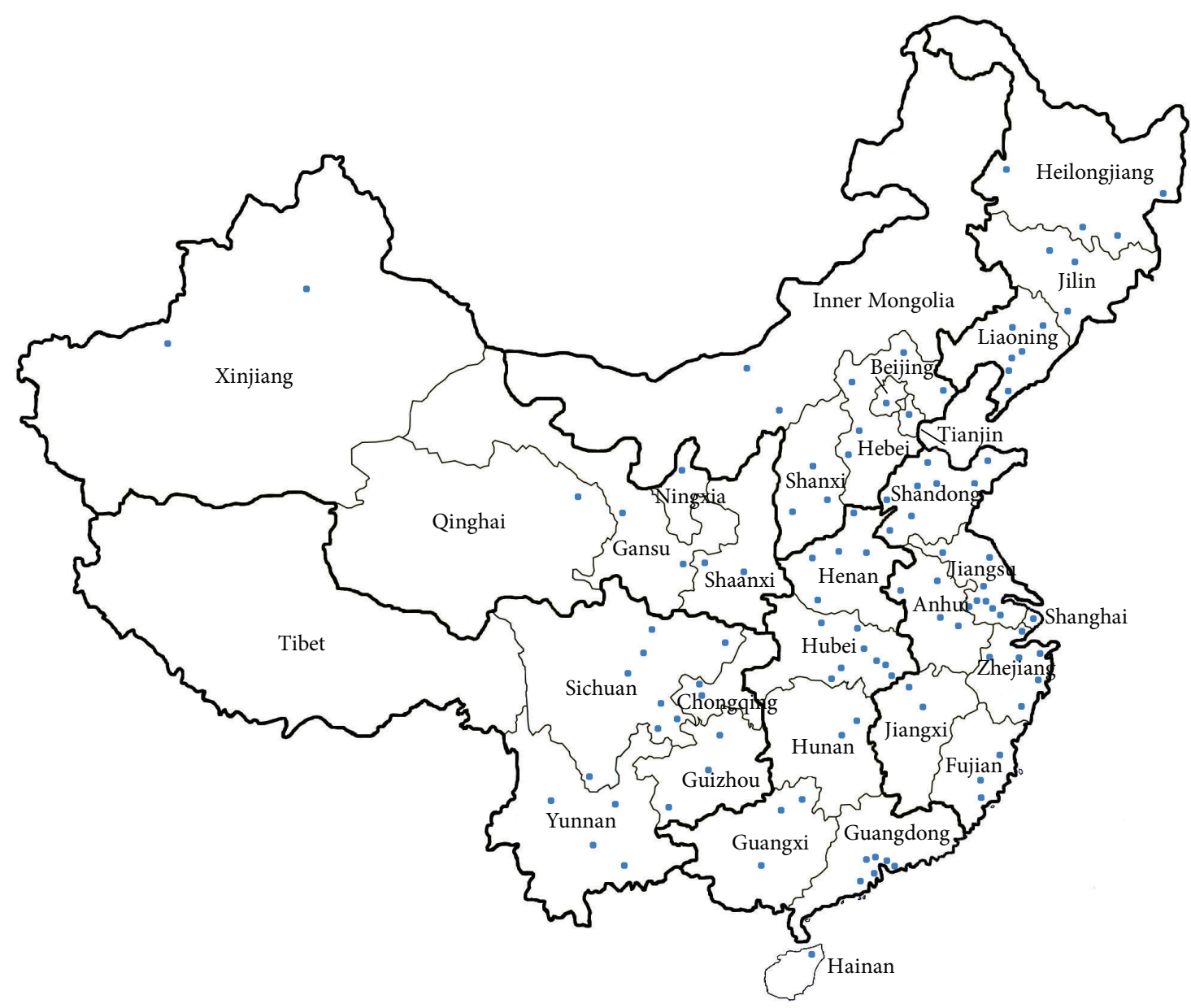

FIGURE 2: Distribution of HIV national sentinel surveillance sites for men who have sex with men in China. The blue dots represent the location of 109 sentinel surveillance sites in 2011.

\section{Community Responses to HIV among Chinese MSM}

6.1. Development of Community-Based Organizations in China. Since early 1990s, several gay men voluntarily joined together and started to advocate for HIV prevention and awareness and knowledge of HIV/AIDS to the gay community [361]. They established the first telephone hotline "99575 Beijing Tongzhi Hotline" in Beijing, this hotline was served by health educators in order to provide health promotion, counselling services, harm reduction strategies, and safe sex practices to the local MSM community [102]. In 1997, a group of MSM established a community-based program named "Friends" in collaboration of with specialists and professions from public health, sociology, psychology, and legal areas. This program led to the subsequent publication of a bimonthly magazine named "Friend Exchange" in the following year. This magazine provided a comprehensive collection of information on HIV/AIDS, sexual orientation, academic researches, and personal life experiences of homosexual individuals [362-364]. This program gradually expanded and was transformed into the first registered communitybased organization (CBO) for gay and lesbians (i.e., the Beijing Gender Health Education Institute) in Beijing in 2002 [102]. The institute provided training program to promote self-acceptance of sexual identity and social justice and provide related psychological counselling to its participants. Furthermore, with the support of the Fifth Round of AIDS Program of Global Fund in China in 2005, this program had been significantly scaled up to promote HIV prevention and AIDS treatment among MSM [365]. The success of this program has led to the Chinese Ministry of Health's decision to explicitly request all level of health departments to initiate health intervention programs among MSM [363]. Consequently, a large number of grassroots CBOs for MSM have been then established in major urban cities. A large cross-sectional study among MSM in 61 cities was conducted in 2009 to understand the geographical disparities of HIV epidemic and risk behaviours among the population [48], which has initiated a strong collaboration between local CDCs and MSM-targeted CBOs [366]. In 2013, China CDC 
has pledged to provide greater support to $\mathrm{CBO}$ s participating in HIV/AIDS prevention activities [352].

6.2. The Unique Role of CBOs in HIV Surveillance and Prevention. CBOs play a unique role in confronting the HIV/AIDS epidemic among MSM in China. First, unlike other high-risk populations such as female sex workers and injecting drug users, gay relationships are not illegal in China and hence the Chinese government cannot exert authority over this population. In general, it is difficult for individual MSM to establish a well-trusted relationship with governmental bodies [359]. Due to social discrimination towards homosexuality and people living with HIV (PLHIV), most of Chinese MSM will conceal their homosexuality publicly [103]. Without the mediation of well-trusted CBOs that are representative of the MSM community, it has become apparent that the Chinese government cannot access to this population and conduct an effective epidemic surveillance [367-369]. Second, in comparison with the governmental institutions, CBOs are much less authoritative and more extensively rooted in the MSM community [370]. These organisations are capable of mobilising multiple channels through private entertainment establishments (e.g., gay bars, saunas), public venues (e.g., parks and clubs), and mass communication media (e.g., internet and hotlines) to effectively provide peer-education services, free condom and lubricant distribution, and peer-counselling and promote HIV voluntary counselling and testing (VCT) [371]. Third, CBOs are usually at a better position to engage the government to advocate for changes in health policies, allocation of resources, and rights for their community.

6.3. Barriers and Challenges Facing the Development of CBOs. Development of CBOs in MSM community faces several challenges. First, financial restriction obstructs the official registration of CBOs [372]. In particular, establishing a CBO at a national or local level in China requires a minimum of RMB 100,000 (US\$ 15,000) and RMB 30,000 (US\$ 4,500), respectively [373]. Due to the lack of enabling financial, political, and legal environment [372], very few of them obtain registered status [374]. As a result, they are not eligible to apply for governmental funds and are at risk to be banned by the Chinese government. Currently, the operation and development of MSM-based CBOs are mainly supported by external funding bodies such as Global Fund to Fight AIDS, Tuberculosis and Malaria, which is the largest funding source for Chinese CBOs $[375,376]$. With the gradual withdraw of Global Fund and eventual termination in China in 2013, many of these CBOs is expected to dissolve in the absence of replacement funding from the government $[377,378]$. Second, CBOs are lacking capacity [379-381]. Most of these organizations remain focusing on the primary intervention activities such as condom distribution and health advocacy but have limited experience on financial management, funding application, project planning, management, organization, and supervision [381]. The quick staff turnover, lack of collaboration with governmental bodies and research institutions also limit its development and expansion in the community [211].

\section{Scientific Innovations in Responses to HIV among MSM}

Several biobehavioural interventions have been shown to have significant impacts in preventing HIV transmission in recent years. First, male circumcision could significantly reduce $50-60 \%$ of HIV transmission via penile-vaginal sexual intercourse [382-384]. It is estimated that less than $5 \%$ of the total male Chinese population are circumcised [385]. However, 30.7-36.4\% of MSM are willing to undergo circumcision [291, 386, 387]. Second, HIV preexposure prophylaxis (PrEP) may reduce the chance of HIV acquisition during sexual intercourse [388]. Studies showed that only $11.2 \%$ of MSM in Beijing are aware of PrEP but $67.8 \%$ are willing to use PrEP, if it is available in China [389]. An even higher rate of awareness of PrEP (22.1\%) is reported among MSM in the Southwest China, where HIV is most prevalent [390].

\section{Conclusions}

MSM is an emerging highly at risk population for HIV transmission in China. Overlapping homosexual, bisexual, and commercial sexual activities and high-risk drug use behaviours are common among Chinese MSM. Due to the hidden nature of the population and the existing stigma and discrimination associated with HIV infection and homosexuality, Chinese MSM are reluctant to access healthcare and HIV testing services [40]. Hence, it remains a challenge to provide timely diagnosis, care, and treatment to HIV-infected individuals. A substantial scale-up of epidemiological and behavioural surveillance efforts is required. Furthermore, innovative technology-based HIV prevention via mobile apps, Internet, or short message service (SMS) should be promoted to target the unreached MSM subgroups [391]. Over the past decade, both Chinese government and grassroots CBOs have significantly increased their commitment and contribution towards HIV surveillance among MSM. CBOs play an irreplaceable role in the national surveillance effort and its close collaboration with the government is essential for any effective epidemic surveillance and prevention measures among Chinese MSM.

\section{Conflict of Interests}

All authors declare no conflict of interests in this study.

\section{Acknowledgments}

This study was supported by the following grants: the Australian Government Department of Health and Ageing, the University of New South Wales, the World Bank Global HIV/AIDS Program, the Australian Research Council (Grant no. FT0991990), the National Natural Science Foundation of China (Grant no. 81373060), the Australian Postgraduate Awards for EPFC's PhD study, and the Endeavour Research Fellowship (Award ID: 2774_2012) for its support in EPFC's study in China. 


\section{References}

[1] State Council AIDS Working Committee Office (SCAWCO), 2012 China AIDS Response Progress Report, Ministry of Health of the People's Republic of China, Beijing, China, 2012.

[2] H. Shang, J. Xu, X. Han, J. Spero Li, K. C. Arledge, and L. Zhang, "HIV prevention: bring safe sex to China," Nature, vol. 485, no. 7400, pp. 576-577, 2012.

[3] H. Qian, J. E. Schumacher, H. T. Chen, and Y. Ruan, "Injection drug use and HIV/AIDS in China: review of current situation, prevention and policy implications," Harm Reduction Journal, vol. 3, article 4, 2006.

[4] L. Zhang, E. P. Chow, J. Jing et al., "HIV prevalence in China: integration of surveillance data and a systematic review," The Lancet Infectious Diseases, vol. 13, no. 11, pp. 955-963, 2013.

[5] State Council AIDS Working Committee Office (SCAWCO), China 2010 UNGASS Country Progress Report (2008-2009), Ministry of Health of the People's Republic of China, Beijing, China, 2010.

[6] E. P. F. Chow, D. P. Wilson, J. Zhang, J. Jing, and L. Zhang, "Human immunodeficiency virus prevalence is increasing among men who have sex with men in China: findings from a review and meta-analysis," Sexually Transmitted Diseases, vol. 38, no. 9, pp. 845-857, 2011.

[7] S. Baral, F. Sifakis, F. Cleghorn, and C. Beyrer, "Elevated risk for HIV infection among men who have sex with men in lowand middle-income countries 2000-2006: a systematic review," PLoS Medicine, vol. 4, no. 12, p. e339, 2007.

[8] K. Zhang and S. Ma, "Epidemiology of HIV in China," British Medical Journal, vol. 324, no. 7341, pp. 803-804, 2002.

[9] F. Y. Wong, Z. J. Huang, W. Wang et al., "STIs and HIV among men having sex with men in China: a ticking time bomb?" AIDS Education and Prevention, vol. 21, no. 5, pp. 430-446, 2009.

[10] J. T. F. Lau, C. Lin, C. Hao, X. Wu, and J. Gu, "Public health challenges of the emerging HIV epidemic among men who have sex with men in China," Public Health, vol. 125, no. 5, pp. $260-$ 265, 2011.

[11] E. P. Chow, K. I. Iu, X. Fu, D. P. Wilson, and L. Zhang, "HIV and sexually transmissible infections among money boys in China: a data synthesis and meta-analysis," PLoS One, vol. 7, no. 11, Article ID e48025, 2012.

[12] E. P. F. Chow, D. P. Wilson, and L. Zhang, "What is the potential for bisexual men in China to act as a bridge of HIV transmission to the female population? Behavioural evidence from a systematic review and meta-analysis," BMC Infectious Diseases, vol. 11, article 242, 2011.

[13] L. Zhang, E. P. Chow, and D. P. Wilson, "Distributions and trends in sexual behaviors and HIV incidence among men who have sex with men in China," BMC Public Health, vol. 12, no. 1, article 546, 2012.

[14] L. Wang, J. L. Norris, D. M. Li, W. Guo, Z. W. Ding, and N. Wang, "HIV prevalence and influencing factors analysis of sentinel surveillance among men who have sex with men in China, 2003-2011," Chinese Medical Journal, vol. 125, no. 11, pp. 18571861, 2012.

[15] J. T. Lau, J. K. Zhao, X. B. Wu, J. Gu, and C. Hao, “Gay saunas and the risks of HIV and syphilis transmissions in China-results of a meta-analysis," The Journal of Sexual Medicine, vol. 10, no. 3, pp. 642-652, 2013.

[16] X. Chen, Y. Yin, N. Jiang, and B. Wang, "Setting typologies and HIV prevalence among men who have sex with men in
China: implication for surveillance and intervention," Sexually Transmitted Diseases, vol. 39, no. 3, pp. 226-228, 2012.

[17] J. Zhao, L. Chen, W. D. Cai et al., "HIV infection and sexual behaviors among non-commercial men who have sex withmen at different venues," Archives of Sexual Behavior, 2013.

[18] E. P. Chow, D. P. Wilson, and L. Zhang, "The next era of HIV in China: rapidly spreading epidemics among men who have sex with men," Journal of Acquired Immune Deficiency Syndromes, vol. 55, no. 4, pp. e32-e33, 2010.

[19] G. Zeng, Y. Xiao, P. Xu, N. Feng, C. Jin, and F. Lü, "Evaluation of effect of community-based HIV/AIDS interventions among men who have sex with men in eighteen cities, China," Zhonghua Yu Fang Yi Xue Za Zhi, vol. 43, no. 11, pp. 977-980, 2009.

[20] B. Zhang, X. Li, Q. Chu, N. Wang, Z. Wang, S. Zhou et al., "A survey of HIV/AIDS related behaviors among 2250 MSM in nine major cities of China," Chinese Journal of AIDS \& STD, vol. 14, no. 6, pp. 541-547, 2008.

[21] K. R. Davis and S. C. Weller, "The effectiveness of condoms in reducing heterosexual transmission of HIV," Family Planning Perspectives, vol. 31, no. 6, pp. 272-279, 1999.

[22] S. Weller and K. Davis, "Condom effectiveness in reducing heterosexual HIV transmission," Cochrane Database of Systematic Reviews, no. 1, Article ID CD003255, 2002.

[23] S. C. Weller, "A meta-analysis of condom effectiveness in reducing sexually transmitted HIV," Social Science \& Medicine, vol. 36, no. 12, pp. 1635-1644, 1993.

[24] S. D. Pinkerton and P. R. Abramson, "Effectiveness of condoms in preventing HIV transmission," Social Science and Medicine, vol. 44, no. 9, pp. 1303-1312, 1997.

[25] J. T. Fitch, C. Stine, W. D. Hager, J. Mann, M. B. Adam, and J. McIlhaney, "Condom effectiveness: factors that influence risk reduction," Sexually Transmitted Diseases, vol. 29, no. 12, pp. 811$817,2002$.

[26] E. P. F. Chow, D. P. Wilson, and L. Zhang, "Patterns of condom use among men who have sex with men in China: a systematic review and meta-analysis," AIDS and Behavior, vol. 16, no. 3, pp. 653-663.

[27] K. C. Koh, K. Kanagalingam, F. T. Tai, and A. Kamarulzaman, "Sexual practices and HIV prevalence amongst men who have sex with men at a community-based voluntary counseling and testing centre in Malaysia," ISRN Infectious Diseases, vol. 2013, Article ID 247545, 6 pages, 2013.

[28] H. Zou, Z. Wu, J. Yu et al., "Sexual risk behaviors and HIV infection among men who have sex with men who use the internet in Beijing and Urumqi, China," Journal of Acquired Immune Deficiency Syndromes, vol. 53, supplement 1, pp. S81S87, 2010.

[29] C. F. Caceres and G. J. P. van Griensven, "Male homosexual transmission of HIV-1," AIDS, vol. 8, no. 8, pp. 1051-1061, 1994.

[30] Q. He, Y. Xia, H. Fisher Raymond, R. Peng, F. Yang, and L. Ling, "HIV trends and related risk factors among men having sex with men in mainland China: findings from a systematic literature review," Southeast Asian Journal of Tropical Medicine and Public Health, vol. 42, no. 3, pp. 616-633, 2011.

[31] E. P. Chow, J. Jing, Y. Feng et al., "Pattern of HIV testing and multiple sexual partnerships among men who have sex with men in China," BMC Infectious Diseases 2013, vol. 13, article 549, 2013.

[32] J. Legge, The Chinese Classics: With a Translation, Critical and Exegetical Notes, Prolegomena, and Copious Indexes. Volume 2: The Works of Mencius, Clarendon Press, Oxford, UK, 1861. 
[33] W. Zhang, Chinese Economic Reforms and Fertility Behaviour: A Study of a North China Village, China Library, London, UK, 2002.

[34] M. Liu, "Two gay men seeking two lesbians: an analysis of Xinghun (formality marriage) ads on China's Tianya.cn," Sexuality \& Culture, vol. 17, no. 3, pp. 494-511, 2013.

[35] L. Feng, X. Ding, R. Lu et al., "High HIV prevalence detected in 2006 and 2007 among men who have sex with men in China's largest municipality: an alarming epidemic in Chongqing, China," Journal of Acquired Immune Deficiency Syndromes, vol. 52, no. 1, pp. 79-85, 2009.

[36] X. W. Qiao, X. Z. Ma, and Y. Li, "Epidemiological analysis of HIV-VCT service among men who have sex with men in the city of Lanzhou in 2008," Health Vocational Education, vol. 27, no. 22, pp. 104-105, 2009.

[37] S. Q. Qu, D. P. Zhang, Y. H. Wu, H. Zhu, and X. W. Zheng, "Seroprevalence of HIV and risk behaviors among men who have sex with men in a northeast city of China," Chinese Journal of STD \& AIDS Prevention and Control, vol. 8, no. 3, pp. 145-147, 161, 2002.

[38] B. Zhang, X. Li, T. Hu, D. Liu, and T. Shi, "HIV/AIDS interventions targeting men who have sex with men (MSM): theory and practice," Chinese Journal of STD \& AIDS Prevention and Control, vol. 6, no. 3, pp. 155-157, 2000.

[39] B. Zhang, X. Li, Q. Chu, N. Wang, Z. Wang, S. Zhou et al., "Correlation between AIDS and homosexuals: a study of 2046 male homosexuals in nine major cities of China," The Chinese Journal of Human Sexuality, vol. 17, no. 8, pp. 6-10, 2008.

[40] E. P. Chow, L. Gao, F. K. Koo, L. Chen, X. Fu, J. Jing et al., "Exploration of HIV-related sexual behaviours and multiple partnerships among Chinese men who have sex with men living in rural area of Yunnan Province, China: a pilot study," Sexual Health, vol. 10, no. 6, pp. 533-540, 2013.

[41] E. P. Chow, F. K. Koo, and L. Zhang, "Are wives of gay men becoming the next target of HIV infection in China?" Sexually Transmitted Diseases, vol. 40, no. 12, pp. 964-965, 2013.

[42] A. Pandya, S. Pandya, B. Patil, and S. Merchant, "Invisible others': sexual health vulnerabilities of wives of men who have sex with men," Sexuality \& Culture, vol. 16, no. 1, pp. 76-89, 2012.

[43] Q. He, W. Peng, J. Zhang, B. Wang, and J. Wang, "Prevalence of unprotected anal intercourse and unprotected vaginal intercourse among HIV-positive men who have sex with men in China: a meta-analysis," Sexually Transmitted Infections, vol. 88, no. 3, pp. 229-233, 2012.

[44] K. Yun, J. J. Xu, K. H. Reilly et al., "Prevalence of bisexual behaviour among bridge population of men who have sex with men in China: a meta-analysis of observational studies," Sexually Transmitted Infections, vol. 87, no. 7, pp. 563-570, 2011.

[45] E. P. F. Chow, D. P. Wilson, and L. Zhang, "Estimating HIV incidence among female partners of bisexual men in China," International Journal of Infectious Diseases, vol. 16, no. 5, pp. e312-e320, 2012.

[46] Q. He, Y. Wang, P. Lin et al., "Potential bridges for HIV infection to men who have sex with men in Guangzhou, China," AIDS and Behavior, vol. 10, no. 4, supplement, pp. S17-S23, 2006.

[47] C. Jin, "Wives of Homosexual Men in China-A Disadvantaged Group," 2011, http://www.chinadecoded.com/2010/12/02/ wives-of-homosexual-men-in-china-a-disadvantaged-group/.

[48] Z. Wu, J. Xu, E. Liu et al., "HIV and syphilis prevalence among men who have sex with men: a cross-sectional survey of 61 cities in China," Clinical Infectious Diseases, vol. 57, no. 2, pp. 298-309, 2013.
[49] J. Xu, Z. J. Wu, H. B. Zhang et al., "Study on the status Of HIV infection and syphilis infection among MSM In Hefei and its correlation with the social and sexual partner characteristics of MSM," Modern Preventive Medicine, vol. 34, no. 16, pp. 30093011, 3014, 2007.

[50] J. Xu, H. B. Zhang, Y. J. Zheng et al., “The prevalence of syphilis and HIV infection among young men who have sex with men in Hefei City," Chinese Journal of Behavioral Medical Science, vol. 16, no. 3, pp. 205-207, 2007.

[51] G. P. Ji, J. Xu, H. Yao, J. G. He, X. P. Zhang, and X. J. Li, "AIDS knowledge, behavior and HIV prevalence among MSM in Anhui, China," Anhui Journal of Prevent Medicine, vol. 16, no. 5, pp. 335-338, 2010.

[52] X. L. Cheng, F. H. Wang, and Y. K. Xiao, "Analysis on the data of HIV sentinel surveillance in 2002-2006 in Anhui Province," Anhui Journal of Prevent Medicine, vol. 15, no. 2, pp. 81-84, 2009.

[53] J. Xu, H. B. Zhang, Y. J. Zheng et al., "Demand and use of VCT service among MSM," Chinese Journal of Public Health, vol. 23, no. 9, pp. 1040-1042, 2007.

[54] D. M. Li, X. H. Shun, and G. Zeng, "National HIV sentinel surveillance for high risk population in China in 2005," Chinese Journal of AIDS \& STD, vol. 13, no. 1, pp. 1-3, 2007.

[55] H. Y. Huang, X. P. Zhang, Y. Li, Z. W. Hu, and Z. R. Li, "Study on the HIV, syphilis and hepatitis $C$ infections and sexual behavior characteristics among men who have sex with men in Hefei," Modern Preventive Medicine, vol. 38, no. 10, pp. 1933-1935, 1938, 2011.

[56] H. M. Yuan, L. Cheng, and M. W. Zhang, "AIDS-related knowledge, attitudes and practices among men who have sex with men in Yushan District of Anhui Province," Anhui Journal of Prevent Medicine, vol. 17, no. 3, pp. 239-240, 2011.

[57] F. H. Wang, X. L. Cheng, Y. K. Xiao, B. Su, and G. P. Ji, “Analysis of the results of HIV/AIDS surveillance among men who have sex with men in Anhui Province in 2009-2010," Journal of Disease Control \& Prevention, vol. 15, no. 8, pp. 685-688, 2011.

[58] H. Liu, N. Wang, Q. Zhang, Y. Shao, T. Wu, Y. Liu et al., "Study of HIV and syphilis infection situation and sexual behavioral characteristics among 416 MSM," Chinese Journal of AIDS \& STD, vol. 13, no. 3, pp. 230-232, 234, 2007.

[59] X. Zhang, C. Wang, W. Hengwei et al., "Risk factors of HIV infection and prevalence of co-infections among men who have sex with men in Beijing, China," AIDS, vol. 21, supplement 8, pp. S53-S57, 2007.

[60] X. Ma, Q. Zhang, X. He et al., "Trends in prevalence of HIV, syphilis, hepatitis $\mathrm{C}$, hepatitis $\mathrm{B}$, and sexual risk behavior among men who have sex with men: results of 3 consecutive respondent-driven sampling surveys in Beijing, 2004 through 2006," Journal of Acquired Immune Deficiency Syndromes, vol. 45 , no. 5 , pp. 581-587, 2007.

[61] X. Li, W. Shi, D. Li et al., "Predictors of unprotected sex among men who have sex with men in Beijing, China," Southeast Asian Journal of Tropical Medicine and Public Health, vol. 39, no. 1, pp. 99-108, 2008.

[62] H. Liu, Y. Liu, and Y. Xiao, "A survey on knowledge, attitude, belief and practice related to HIV/AIDS among MSM," Chinese Journal of STD \& AIDS Prevention and Control, vol. 7, no. 5, pp. 289-291, 2001.

[63] Y. Ruan, F. Luo, Y. Jia et al., "Risk factors for syphilis and prevalence of HIV, hepatitis B and C among men who have sex with men in Beijing, China: implications for HIV prevention," AIDS and Behavior, vol. 13, no. 4, pp. 663-670, 2009. 
[64] Y. Ruan, Y. Jia, X. Zhang et al., "Incidence of HIV-1, syphilis, hepatitis $\mathrm{B}$, and hepatitis $\mathrm{c}$ virus infections and predictors associated with retention in a 12-month follow-up study among men who have sex with men in Beijing, China," Journal of Acquired Immune Deficiency Syndromes, vol. 52, no. 5, pp. 604610, 2009.

[65] Y. Guo, X. Li, X. Fang et al., "A comparison of four sampling methods among men having sex with men in China: implications for HIV/STD surveillance and prevention," AIDS Care, vol. 23, no. 11, pp. 1400-1409, 2011.

[66] Z. H. Zhou, S. M. Li, Y. J. Liu et al., "Survey of HIV and syphilis infection and influential factors associated with unprotected anal intercourse in men who have sex with men in Beijing," China Tropical Medicine, vol. 10, no. 1, pp. 10-12, 2010.

[67] H. Y. Lu, X. Y. Ma, Y. C. Liu et al., "A survey of HIV/STDs prevalence in $200 \mathrm{MSM}$ and related factors in Beijing," Chinese Journal of AIDS \& STD, vol. 14, no. 5, pp. 467-470, 2008.

[68] Y. Bao, Y. Zhang, J. Zhao, J. Sun, and H. Tan, "HIV infection and KAP status among men who have sex with men in 14 Chinese cities," Zhonghua Yu Fang Yi Xue Za Zhi, vol. 43, no. 11, pp. 981983, 2009.

[69] J. Xu, D. Han, Z. Liu et al., "The prevalence of HIV infection and the risk factors among MSM in 4 cities, China," Zhonghua Yu Fang Yi Xue Za Zhi, vol. 44, no. 11, pp. 975-980, 2010.

[70] Q. Chen, Y. Li, Y. Sun, H. Lu, S. Shen, and Y. Jiang, "A survey of HIV prevalence and incidence in men who have sex with men in Beijing, 2008-2009," Chinese Medicial Biotechnology, vol. 6, no. 4, pp. 270-273, 2011.

[71] Y. Liu, S. Jiang, Y. Hu, L. Song, M. Yu, and S. M. Li, "Characteristics of sexual behaviors and infection status of AIDS and other sexually transmitted diseases among men who have sex with men in 2009 in Beijing," Zhonghua Yu Fang Yi Xue Za Zhi, vol. 45, no. 11, pp. 971-974, 2011.

[72] J. D. Zheng, L. Pang, J. Xu, K. M. Rou, D. Xiao, and Z. Y. Wu, "Study on the prevalence of HIV and AIDS-related risky sexual behaviors among male university students who have sex with men in Beijing, China," Zhonghua Liu Xing Bing Xue Za Zhi, vol. 32, no. 4, pp. 337-340, 2011.

[73] X. X. Chen, J. P. Yu, M. Li, and Q. X. Su, "Survey on infection of HPV and HIV among men who have sex with men in Beijing," International Journal of Virology, vol. 18, no. 4, pp. 101-105, 2011.

[74] S. Li, Z. Zhou, S. Jiang et al., "Incidence and risk factors of HIV and syphilis seroconversion among men who have sex with men in Beijing," Zhonghua Yu Fang Yi Xue Za Zhi, vol. 45, no. 2, pp. 118-122, 2011.

[75] W. H. Wang, L. Ming, S. L. Jiang et al., “The prevalence and dynamics of human immunodeficiency virus-1 subtypes among men who have sex with men in Beijing," Chinese Journal of Infectious Diseases, vol. 30, no. 11, pp. 673-676, 2012.

[76] S. Wei, H. Zhang, J. Wang et al., "HIV and syphilis prevalence and associated factors among young men who have sex with men in 4 cities in China," AIDS and Behavior, vol. 17, no. 3, pp. 1151-1158, 2013.

[77] Z. Cao, H. B. Zhang, M. She et al., "Prevalence of HIV infection and sexual behaviors with both men and women among currently married men who have sex with men," Zhonghua Liu Xing Bing Xue Za Zhi, vol. 33, no. 5, pp. 488-491, 2012.

[78] Z. Yan, X. Y. Sun, and X. Zhou, "Analysis of the population for voluntary HIV counseling and testing in Xicheng District of Beijing," Occupation and Health, vol. 28, no. 20, pp. 2500-2502, 2012.
[79] S. Fan, H. Lu, X. Ma et al., "Behavioral and serologic survey of men who have sex with men in Beijing, China: implication for HIV intervention," AIDS Patient Care and STDs, vol. 26, no. 3, pp. 148-155, 2012.

[80] Y. J. Gao, M. R. Yu, S. M. Li et al., "Prevalence and predictors of HIV, syphilis and herpes simplex type 2 virus (HSV-2) infections among men who have sex with men (MSM) in Beijing," Chinese Journal of Public Health, vol. 28, no. 4, pp. 451453, 2012.

[81] J. Tao, Y. Ruan, L. Yin et al., "Sex with women among men who have sex with men in China: prevalence and sexual practices," AIDS Patient Care and STDs, vol. 27, no. 9, pp. 524-528, 2013.

[82] L. G. Feng, X. B. Ding, J. Xu et al., "Study on HIV, syphilis and $\mathrm{HCV}$ prevalence and its associated factors among internet MSM comparison to non-internet MSM in Chongqing," Journal of Tropical Medicine, vol. 10, no. 1, pp. 78-82, 2010.

[83] H. Zeng, X. Ding, J. Xu et al., "Status and demand on HIV/AIDS control among men who have sex with men in main districts of Chongqing," Academic Journal of Second Military Medical University, vol. 32, no. 5, pp. 494-499, 2011.

[84] C. Zhou, X. B. Ding, L. Feng et al., "Study on the prevalence and associated factors of HIV and syphilis among 1166 men who have sex with men," Modern Preventive Medicine, vol. 38, no. 5, pp. 815-820, 2011.

[85] M. Han, L. Feng, Y. Jiang et al., "Application of rapid test, combined HIV antigen/antibody EIA and pooled PCR in the detection of HIV-1 among MSM," International Journal of Laboratory Medicine, vol. 32, no. 11, pp. 1185-1186, 2011.

[86] C. M. Li, Y. J. Jia, J. B. Liu, B. Xian, and Y. Xiao, "Prevalence and predictors of unprotected anal sex among men who have sex with men in Chongqing municipality, China," Chinese Journal of Public Health, vol. 27, no. 3, pp. 351-352, 2011.

[87] Y. Zhang, P. Chen, R. Lu et al., "Prevalence of HIV among men who have sex with men in Chongqing, China, 2006-2009: cross-sectional biological and behavioural surveys," Sexually Transmitted Infections, vol. 88, no. 6, pp. 444-450, 2012.

[88] S. Zhou, L. G. Feng, X. B. Ding, and H. Y. Xiong, "Analysis of HIV infection rate and its influencing factors among male migrant workers who have sex with men," Acta Academiae Medicinae Militaris Tertiae, vol. 35, no. 1, pp. 46-49, 2013.

[89] Y. Yan and Y. W. Zhang, "The comparative study of HIV awareness among prostitutes in two cities," Journal of Inner Mongolia University for Nationalities (Natural Sciences), vol. 18, no. 5, pp. 83-84, 2012.

[90] X. Y. Zhao, K. J. Chen, L. Chen et al., "Analysis on HIV prevalence and its associated factors among men who have sex with men in Yongchuan District, Chongqing," Modern Preventive Medicine, vol. 40, no. 3, pp. 500-503, 2013.

[91] C. Zhou, H. F. Raymond, X. Ding et al., "Anal sex role, circumcision status, and HIV infection among men who have sex with men in Chongqing, China," Archives of Sexual Behavior, vol. 42, no. 7, pp. 1275-1283, 2013.

[92] Y. Zhao and C. Y. Peng, "Analysis on AIDS monitoring results of high risk groups in Jiangbei District of Chongqing during 20112012," International Journal of Laboratory Medicine, vol. 34, no. 11, pp. 1398-1399, 2013.

[93] M. Jia, H. Luo, Y. Ma et al., "The HIV epidemic in Yunnan Province, China, 1989-2007," Journal of Acquired Immune Deficiency Syndromes, vol. 53, supplement 1, pp. S34-S40, 2010.

[94] C. T. Gong and Q. H. Zhang, "Results of AIDS monitoring of 252 MSM in Quanzhou City," China Tropical Medicine, vol. 10, no. 12, pp. 1496-1497, 2010. 
[95] F. X. Wang and L. L. Wang, "Survey of awareness of knowledge/behaviors about AIDS among men having sex with men and their HIV infection status," Journal of Preventive Medicine, vol. 26, no. 6, pp. 464-465, 2010.

[96] G. Chen, Y. J. Pan, L. Lin, C. Y. Zhang, J. Zheng, and Y. S. Yan, "Prevalence of HIV/AIDS and related high risk behaviours among men who have sex with men in Fujian Province," Chinese Journal of Preventive Medicine, vol. 45, no. 1, pp. 86-88, 2011.

[97] L. X. Zheng, J. C. Que, and Q. J. Chen, "Surveillance of HIV infection and associated risk behaviors among men who have sex with men in Longyan City of Fujian Province, 2010-2011," Strait Journal of Preventive Medicine, vol. 18, no. 4, pp. 34-35, 2012.

[98] P. P. Yan, C. Y. Zhang, F. F. Liang et al., "Study on men who have sex with men for HIV infection prevalence and the incidence in Fujian in 2012," Strait Journal of Preventive Medicine, vol. 19, no. 2, pp. 1-2, 5, 2013.

[99] Y. Li, J. J. Chen, L. P. Gu, and W. L. Gao, "Survey of HIV/SY infection and KABP related to AIDS among the MSM in Lanzhou," Chinese Medical Science \& Health, vol. 8, pp. 1-3, 2007.

[100] Y. Xiao, J. Sun, C. Li et al., "Prevalence and correlates of HIV and syphilis infections among men who have sex with men in seven Provinces in China with historically low HIV prevalence," Journal of Acquired Immune Deficiency Syndromes, vol. 53, supplement 1, pp. S66-S73, 2010.

[101] J. J. Chen, X. Y. Zhang, X. Y. Chen et al., "The analysis of influence factors of HIV in MSM in Lanzhou," The Chinese Journal of Dermatovenereology, vol. 25, no. 12, pp. 954-957, 2011.

[102] Q. He, Y. Wang, P. Lin, Z. B. Zhang, X. X. Zhao, and H. F. Xu, "KAP study on AIDS among men who have sex with men in Guangzhou, Guangdong Province," Chinese Journal of Disease Control \& Prevention, vol. 9, no. 2, pp. 106-108, 2005.

[103] W. Cai, J. Zhao, J. Zhao et al., "HIV prevalence and related risk factors among male sex workers in Shenzhen, China: results from a time-location sampling survey," Sexually Transmitted Infections, vol. 86, no. 1, pp. 15-20, 2010.

[104] W. D. Cai, T. J. Fen, J. Q. Tan et al., "A survery of the characteristics and STD/HIV infection of homosexuality in Shenzhen," Modern Preventive Medicine, vol. 32, no. 4, pp. 328330, 2005.

[105] T. Feng, X. Liu, Y. Cai et al., "Prevalence of syphilis and human immunodeficiency virus infections among men who have sex with men in shenzhen, China: 2005 to 2007," Sexually Transmitted Diseases, vol. 35, no. 12, pp. 1022-1024, 2008.

[106] Y. Wang, H. B. Zhang, Z. G. Gui et al., "Analysis of behavior of MSM population and the biological monitoring result in Mianyang City," Modern Preventive Medicine, vol. 35, no. 19, pp. 3780-3783, 3789, 2008.

[107] L. P. Dai, Y. H. Jiang, and C. H. Gong, "The characteristic of behavior and HIV prevalence among 1315 men who have sex with men in Guangzhou," Chinese Journal of AIDS \& STD, vol. 17, no. 1, pp. 35-37, 2011.

[108] F. Zhong, P. Lin, H. Xu et al., "Possible increase in HIV and syphilis prevalence among men who have sex with men in Guangzhou, China: results from a respondent-driven sampling survey," AIDS and Behavior, vol. 15, no. 5, pp. 1058-1066, 2011.

[109] T. Wang, X. H. Lai, L. Li, C. Y. Chen, and B. H. He, "Survey on AIDS/STD risk behaviors and prevalence among men who have sex with men in Zhongshan, Guangdong," Practical Preventive Medicine, vol. 17, no. 7, pp. 1261-1263, 2010.

[110] F. Wen, F. Zong, W. B. Cheng, K. Gao, B. L. Luo, and H. F. Xuh, "HIV and current syphilis prevalence and related factors among men who have sex with men in Guangzhou," South China Journal of Preventive Medicine, vol. 36, no. 2, pp. 19-23, 2010.

[111] P. Lin, Y. Wang, J. Li, X. B. Fu, and L. M. Diao, "HIV/AIDS prevalence and control strategies in Guangdong Province," South China Journal of Preventive Medicine, vol. 34, no. 5, pp. $1-5,2008$.

[112] Y. H. Gong, S. H. Chen, Z. M. Liang, and D. D. Sui, "Study on HIV infection and related high-risk behaviors among men who have sex with men in Foshan City, Guangdong Province," South China Journal of Preventive Medicine, vol. 37, no. 1, pp. 31-33, 2011.

[113] Y. Jiang and L. Dai, "Analysis of HIV infection and its associated factors among 1454 men who have sex with men," Chinese Community Doctors, vol. 13, no. 22, pp. 331-332, 2011.

[114] Z. Q. Nie, P. Lin, Y. Li, and Y. Wang, "Surveillance of AIDS highrisk people in Guangdong Province, 2009," Journal of Tropical Medicine, vol. 11, no. 1, pp. 29-31, 45, 2011.

[115] S. C. Liu, L. Chen, W. D. Cai et al., "HIV and syphilis infection and high-risk behaviors among men who have sex with men in Shenzhen City," Chinese Journal of Public Health, vol. 27, no. 7, pp. 908-910, 2011.

[116] Y. M. Qin, G. Liu, X. K. Yang, Y. B. Zhang, and J. G. Tan, "Voluntary AIDS counseling and testing service in Shenzhen from 2008 to 2010," Journal of Tropical Medicine, vol. 12, no. 3, pp. 338-340, 2012.

[117] W. Jie, L. Ciyong, D. Xueqing, W. Hui, and H. Lingyao, "A syndemic of psychosocial problems places the msm (men who have sex with men) population at greater risk of HIV infection," PLoS ONE, vol. 7, no. 3, Article ID e32312, 2012.

[118] Q. Zhang, P. J. Deng, Y. J. Geng et al., "Study on HIV/syphilis infections among men who have sex with men and their behavioral feature," China Tropical Medicine, vol. 12, no. 2, pp. 219-220, 2012.

[119] B. F. Chen, J. Y. Zhong, Q. L. Zhang et al., "Investigation on AIDS-related knowledge and behavior of MSM in Dongguan City," Journal of Tropical Medicine, vol. 12, no. 1, pp. 108-111, 2012.

[120] L. P. Dai, Y. X. Lin, Q. Liu, Y. H. Jiang, C. H. Gong, and J. J. Sha, "Characteristics of sexual behavior and HIV infection among 1472 MSM with different gender role in Guangzhou City," Chinese Journal of Public Health, vol. 29, no. 2, pp. 256258, 2013.

[121] Y. H. Lai, Y. M. Cai, Y. J. Song, X. Zheng, and F. C. Hong, "Characteristics of high risk behavior and syphilis/HIV infection among MSM in Shenzhen in 2011," China Tropical Medicine, vol. 13, no. 2, pp. 226-227, 233, 2013.

[122] Y. H. Lai, Y. M. Cai, Y. J. Song, and F. C. Hong, "HIV/syphilis infection and high risk behaviors among men who have sex with men previous to be money boys," China Tropical Medicine, vol. 13, no. 6, pp. 680-683, 2013.

[123] D. D. Song, H. B. Zhang, J. Wang et al., "The prevalence of HIV infection and sexual behaviors among men who have sex with men and women in Chengdu and Guangzhou, China," Zhonghua Liu Xing Bing Xue Za Zhi, vol. 33, no. 4, pp. 368-373, 2012.

[124] K. J. Zhu, M. Du, J. T. Zhang, G. Yao, and F. Liu, "Analysis on HIV prevalence and the related risk behaviors among MSM in Zhuhai City," Practical Preventive Medicine, vol. 19, no. 8, pp. 1261-1263, 2012.

[125] S. H. Chen, J. Zhou, and J. J. Zhu, "Investigation of STI among some Men Who Have Sex with Men in Nanning City in 2006," Preventive Medicine Tribune, vol. 13, no. 9, pp. 772-774, 2007. 
[126] G. H. Lan, W. Liu, Q. Y. Zhu, F. X. Liang, and Y. Zhou, "To analyze the surveillance results of immigrant MSM in Guangxi," Applied Preventive Medicine, vol. 15, no. 3, pp. 168-170, 2009.

[127] S. H. Chen, J. Q. Zhu, and N. H. Yang, "Investigation on HIV and STI infections among men who have sex with men in Nanning City during 2006-2008," Occupation and Health, vol. 26, no. 1, pp. 56-58, 2010.

[128] S. H. Chen, J. J. Zhu, and J. Li, "Investigation on knowledge of HIV/AIDS and related behaviors character among men who have sex with men in Nanning, Guangxi," Chinese Journal of Disease Control \& Prevention, vol. 14, no. 2, pp. 130-133, 2010.

[129] X. Q. Wen, J. Q. Jiang, Z. K. Zhang, and W. Jiang, "Survey of HIV/AIDS knowledge, high risk behaviors and serology among 315 men who have sex with men in Guilin in 2008," China Tropical Medicine, vol. 10, no. 10, pp. 1194-1195, 2010.

[130] Z. K. Zhang, X. Q. Wen, W. Chen, W. Jiang, and Y. Zhou, "Survey on HIV/AIDS high-risk behaviors among men having sex with men in Guilin," Disease Surveillance, vol. 25, no. 3, pp. 213-215, 2010.

[131] Y. Bai, W. D. Feng, and Q. H. Wei, "Survey of infectious status of HIV, HCV and syphilis in MSM in Liuzhou in 2007-2008," China Tropical Medicine, vol. 9, no. 12, pp. 2275-2276, 2009.

[132] W. J. Lu, W. Liu, Q. Y. Zhu, G. H. Lan, and F. Li, "Analysis of the results of comprehensive surveillance in AIDS-related high risk groups in 20 cities/counties of Guangxi in 2007," Chinese Journal of AIDS \& STD, vol. 14, no. 6, pp. 583-586, 2008.

[133] G. H. Lan, W. Liu, Q. Y. Zhu et al., "Risk factor analysis of syphilis infection among MSM in Guangxi," Modern Preventive Medicine, vol. 8, no. 22, pp. 4586-4588, 2011.

[134] G. H. Lan, W. Liu, Q. Y. Zhu, Y. Chen, F. X. Liang, and Y. M. Huang, "Analysis of HIV/STI sentinel surveillance among men who have sex with men in Guangxi," Journal of Applied Preventive Medicine, vol. 18, no. 4, pp. 238-240, 2012.

[135] Q. X. Nong, S. Jian, Y. F. Xu et al., "Prevalence of HIV infection and its risk factors among MSM in Nanning City," Chinese Journal of Public Health, vol. 29, no. 5, pp. 682-684, 2013.

[136] W. Chen, Y. Zhou, W. Jiang, X. Q. Wen, and Z. K. Zhang, "Monitoring of HIV/AIDS among MSM in Guilin City, Guangxi in 2010," China Tropical Medicine, vol. 12, no. 1, pp. 58-60, 2012.

[137] Y. J. Zhou, Y. Cui, X. J. Zhang et al., "Analysis HIV/AIDS voluntary counseling and testing of Guangxi in 2011," Journal of Applied Preventive Medicine, vol. 19, no. 2, pp. 71-75, 2013.

[138] W. B. Zheng, Q. Y. Zhu, G. H. Lan, J. H. Zhu, and B. Q. Dong, "Efficacy of AIDS intervention service among MSM in Guangxi and its influential factors," China Tropical Medicine, vol. 13, no. 2, pp. 175-179, 2013.

[139] C. G. Lu, F. Yuan, Z. Shi et al., "The study of HIV infection and KABP about AIDS among the MSM in Guiyang City," Guizhou Medical Journal, vol. 30, no. 3, pp. 202-204, 2006.

[140] J. Zhou, J. J. Zhu, H. Bin et al., "A survey of HIV/STD, HBV and HCV infections and risk behaviors among MSM in two central districts of Guiyang City," Chinese Journal of AIDS \& STD, vol. 14, no. 1, pp. 47-48, 51, 2008.

[141] C. G. Lu, F. Yuan, Z. H. Shi et al., "HIV infection survey among MSM," Chinese Journal of Public Health, vol. 2, no. 11, pp. 13201321, 2006.

[142] C. G. Lu, J. Z. Yang, F. Yuan, X. Y. Li, Z. H. Shi, and S. Y. Hu, "A study among MSM from a region of Guizhou Province," Guizhou Medical Journal, vol. 31, no. 5, pp. 462-463, 2007.

[143] C. X. Zhou, Z. P. Pan, Z. Y. Chen, and H. J. Guo, "Results analysis of AIDS sentinel surveillance in Zunyi City, 2010,"
Jiangsu Journal of Preventive Medicine, vol. 22, no. 3, pp. 11-13, 2011.

[144] M. Zheng, Y. M. Yao, L. M. Shen, O. Qin, and J. Zhou, "Survey of HIV/AIDS infection among men who have sex with men in Guiyang City of Guizhou Province," Guizhou Medical Journal, vol. 35, no. 9, pp. 830-831, 2011.

[145] F. Feng, Z. Q. Wang, S. P. Huang, J. G. Lu, Z. W. Lin, and X. Zhong, "Investigation on aids knowledge, attitude and practice characteristics of MSM group and HIV/syphilis infection situation," Modern Preventive Medicine, vol. 36, no. 15, pp. 29022903, 2909, 2009.

[146] B. He, F. Feng, S. F. Zhang et al., "Prevalences of HIV and syphilis infection among MSM in Haikou," Chinese Journal of Public Health, vol. 27, no. 4, pp. 480-482, 2011.

[147] L. F. Chen, Z. Chen, X. L. Tang, Z. L. Lin, and Y. Y. Chen, "Epidemiological investigation of aids in men who have sex with men in Sanya in 2012," China Tropical Medicine, vol. 13, no. 7, pp. 829-831, 2013.

[148] K. Rou, S. G. Sullivan, P. Liu, and Z. Wu, "Scaling up prevention programmes to reduce the sexual transmission of HIV in China," International Journal of Epidemiology, vol. 39, supplement 2, pp. ii38-ii46, 2010.

[149] C. H. Wang, M. J. Jiang, G. J. Lu, and G. Bin, "HIV epidemic spread between male homosexuals in the city of Chengde," Chinese Journal of Health Laboratory Technology, vol. 17, no. 5, pp. 883-884, 2007.

[150] X. L. Wang, J. K. He, H. H. Su, H. Z. Cao, Q. J. Zhang, and G. L. Zhao, "HIV and syphilis infection in male homosexuality in Tangshan City," Chinese Journal of Public Health, vol. 25, no. 7, pp. 787-788, 2009.

[151] Z. M. Tao, C. H. Wang, Q. Zeng, B. Guo, G. K. Li, and H. J. Yuan, "HIV serology examination analysis among 169 men who have sex with men," Medical Information, vol. 2010, no. 23, pp. 288289, 2010.

[152] C. H. Wang, Y. H. Yang, G. J. Lu et al., "Intervene male-male sexual contact AIDS high dangerous behavior and evaluate effectiveness of intervention," Chinese Journal of Health Laboratory Technology, vol. 17, no. 12, pp. 2291-2292, 2007.

[153] L. Liang, Z. Q. Chen, X. F. Miao, B. J. Li, G. Y. Bai, and H. R. Zhao, "An investigation of HIV infections among men who have sex with men," Hebei Medical Journal, vol. 31, no. 15, pp. 19911992, 2009

[154] Q. J. Zhang, W. D. Lv, J. K. He, and H. Z. Cao, "Analysis of MSM HIV antibody in Tangshan during 2008-2009," Chinese Journal of Health Laboratory Technology, vol. 20, no. 5, pp. 1184-1185, 2010 .

[155] W. Guo, A. Song, H. Meng, L. Pang, K. Rou, and Z. Wu, "Survey on AIDS/STD risk behaviors and prevalence among men who have sex with men in Langfang, Hebei," Zhonghua Liu Xing Bing Xue Za Zhi, vol. 29, no. 6, pp. 545-547, 2008.

[156] X. M. Li, Z. X. Xu, Z. S. Wang, and F. B. Liu, "Analysis of HIV infection among different population in Xingtai City of Hebei Province, 2009-2012," Hebei Medical Journal, vol. 35, no. 16, pp. 2505-2506, 2013.

[157] Z. X. Xu, "HIV/HCV/syphilis infection and sexual behavioral characteristics among MSM in rural areas of Xingtai City," Modern Preventive Medicine, vol. 39, no. 24, pp. 6484-6485, 6487, 2012.

[158] H. P. Zhao, G. M. Wang, and H. Y. Liu, "The investigation report of male-to-male contact during the voluntary consultation in Daolin District of Harebin," Guide of China Medicine, vol. 7, no. 10, pp. 181-183, 2009. 
[159] S. Liu, K. Wang, S. Yao, X. Guo, Y. Liu, and B. Wang, "Knowledge and risk behaviors related to HIV/AIDS, and their association with information resource among men who have sex with men in Heilongjiang Province, China," BMC Public Health, vol. 10, article 250, 2010.

[160] S. Y. Liu, K. L. Wang, S. P. Yao et al., "HIV/AIDS-related knowledge and behaviors and their association with information resource among men who have sex with men in Heilongjiang province," Chinese Journal of Public Health, vol. 26, no. 7, pp. 889-890, 2010.

[161] W. D. Lin and L. Wang, "Report on HIV sentinel surveillance among men who have sex with men in Heilongjiang Province in 2006," Chinese Health Care, vol. 15, no. 12, pp. 122-123, 2007.

[162] Y. Li, K. L. Wang, X. Tong, and H. M. Run, "Analysis on HIV/AIDS national sentinel surveillance sites data in high-risk populations in Heilongjiang in 2010," Chinese Primary Health Care, vol. 25, no. 5, pp. 59-61, 2011.

[163] J. Wang, C. Luo, and Y. C. Wen, "HIV infection and related risk behaviors among MSM in Harbin," Chinese Journal of AIDS \& STD, vol. 14, no. 1, p. 75, 2008.

[164] J. D. Zhang, Y. B. Sun, S. Wang, H. J. Liu, L. J. Li, and Y. C. Wen, "HIV and syphilis infections among 121 men who have sex with men in Harbin," Chinese Journal of AIDS \& STD, vol. 14, no. 1, p. 69, 2008.

[165] K. Wang, H. Yan, Y. Liu, Z. Leng, B. Wang, and J. Zhao, "Increasing prevalence of HIV and syphilis but decreasing rate of self-reported unprotected anal intercourse among men who had sex with men in Harbin, China: results of five consecutive surveys from 2006 to 2010," International Journal of Epidemiology, vol. 41, no. 2, pp. 423-432, 2012.

[166] L. Zhang, D. Zhang, B. Yu et al., "Prevalence of HIV infection and associated risk factors among men who have sex with men (MSM) in Harbin, P. R. China," PLoS ONE, vol. 8, no. 3, Article ID e58440, 2013.

[167] N. Li, Z. Wang, G. Q. Sun, and D. Y. Sun, "Analysis of HIV/AIDS sentinel surveillance among high risk population in Henan Province in 2006," Chinese Journal of AIDS \& STD, vol. 13, no. 5, pp. 427-429, 2007.

[168] J. C. Shi, Q. C. Lu, and T. Zhao, "Analysis of the knowledge and infection on AIDS among the MSM in Nanyang City," Henan Journal of Preventive Medicine, vol. 21, no. 6, pp. 405-406, 416, 2010.

[169] M. Wang, Z. Wang, S. H. Wu, D. Y. Sun, and B. C. Liu, "Analysis of the status of HIV voluntary counseling and testing (VCT) in 2009 in Henan Province," Chinese Journal of Clinicians, vol. 5, no. 6, pp. 1611-1615, 2011.

[170] D. Y. Sun, Y. M. Ma, Y. G. Nie, Q. Zhu, and Z. Wang, "Study on HIV/HCV and syphilis infection among MSM in two cities," Chinese Journal of Practical Medicine, vol. 37, no. 21, pp. 10-12, 2010.

[171] J. Liu, B. Qu, M. C. Ezeakile, Y. Zhang, and S. Liang, "Factors associated with HIV infection among men who have sex with men in Henan Province, China: a cross-sectional study," BMC Public Health, vol. 13, article 356, 2013.

[172] X. J. Li, L. X. Cui, J. C. Shi, Y. Zhang, T. Zhao, and L. Ding, "The effectiveness of HIV/AIDS prevention intervention in homosexual men in Nanyang City of Henan Province, 2011," Henan Journal of Preventive Medicine, vol. 24, no. 2, pp. 119-120, 128, 2013.

[173] Z. W. Tian, S. J. Zhao, L. Y. Niu, and J. Yang, "Prevalence of $\mathrm{HIV} /$ syphilis infection and knowledge, behaviors of STD/AIDS among men who have sex with men in Xuchang City," Chinese Journal of Public Health, vol. 29, no. 9, pp. 1330-1333, 2013.

[174] Y. M. Ma, D. Y. Sun, and Z. Wang, "Prevalence of HIV and syphilis among men who have sex with men in Henan Province in 2011," Chinese Journal of Preventive Medicine, vol. 46, no. 11, pp. 1034-1035, 2012.

[175] F. Y. Mao, "Survey on HIV/STI high risk behaviors among 211 men who have sex with men in Yichang City, Huebi Province," World Health Digest, vol. 7, no. 31, pp. 246-247, 2010.

[176] P. L. Liu, Z. Z. Yao, W. D. Shi et al., "Epidemiological study on the status of HIV/STD among MSM in Wuhan City," Chinese Journal of Disease Control and Prevention, vol. 14, no. 9, pp. 917919, 2010.

[177] X. Z. Ke, S. Q. Xiao, J. Deng et al., "HIV infection rate in the different groups of high-risk AIDS population in Huangshi City," Journal of Public Health and Preventive Medicine, vol. 19, no. 4 , p. $59,2008$.

[178] A. Q. Xie, C. Xing, D. Yong, M. X. Wan, and M. J. Zhang, "Results of HIV sentinel surveillance among MSM In Xiangyang City, 2009-2011," China Tropical Medicine, vol. 12, no. 4, pp. 480-481, 2012.

[179] Z. X. Wang, L. Y. Du, and H. P. Chen, "Sexual behaviors and prevalence of HIV/STIs among men who have sex with men in Yichang City of Hubei Province," Journal of Public Health and Preventive Medicine, vol. 24, no. 3, pp. 74-76, 2013.

[180] M. Z. Liao, X. Z. Liu, D. M. Kang et al., "Analysis on the HIV/AIDS surveillance data in Shandong Province in 2009," Preventive Medicine Tribune, vol. 16, no. 5, pp. 398-400, 403, 2010.

[181] X. Meng, C. M. Xie, and X. P. Zheng, "Investigation on AIDS and STD Affection in MSM of Changde," Journal of Tropical Medicine, vol. 10, no. 7, pp. 884-885, 2010.

[182] H. He, D. Zhang, L. Zhou et al., "Behavioral characters \& practice of behavior intervention among 135 MSM in Yueyang," Practical Preventive Medicine, vol. 18, no. 6, pp. 1151-1153, 2011.

[183] L. Qu, J. Y. Yang, X. G. Zhang, Y. R. Yang, and Z. Q. Bao, “Study on HIV and syphilis infections among men who have sex with men in selected cities of Inner Mongolia," Chinese Journal of Epidemiology, vol. 30, no. 10, pp. 1089-1090, 2009.

[184] L. Qu, Y. Gao, J. Liu, J. Yao, Y. Yang, and B. Tao, "Prevalence of HIV infection and its associated factors among 805 MSM in inner Mongolia," Practical Preventive Medicine, vol. 18, no. 11, pp. 2081-2083, 2011.

[185] L. Qu, B. Tao, J. Q. Dai, J. Y. Yang, and Z. Q. Bao, "Evaluation on the comprehensive acquired immunodeficiency syndrome intervention program conducting in men who have sex with men population in Inner Mongolia," Chinese Journal of Infectious Diseases, vol. 29, no. 1, pp. 30-33, 2011.

[186] X. Y. Xu, S. Y. Liu, and J. F. Zhang, "Analysis of AIDS sentinel surveillance in Huhhot in 2009," Journal of Disease Monitor \& Control, vol. 5, no. 7, pp. 393-394, 390, 2011.

[187] L. Qu, Y. M. Gao, J. Y. Yang, B. Tao, Y. R. Yang, and Z. Q. Bao, "Prevalence of HIV/syphilis and associated risk factors among men who have sex with men in Inner Mongolia," Chinese Journal of Preventive Medicine, vol. 46, no. 11, pp. 1040-1043, 2012.

[188] J. L. Hu, L. P. Wu, Z. H. Zhang, and W. Fan, "Investigation of STD/AIDS infection, related knowledge and high-risk sexual behavior among MSM in Huaian City," Journal of Public Health and Preventive Medicine, vol. 19, no. 5, pp. 44-45, 2008. 
[189] J. Jiang, N. Cao, J. Zhang et al., "High prevalence of sexually transmitted diseases among men who have sex with men in Jiangsu Province, China," Sexually Transmitted Diseases, vol. 33, no. 2, pp. 118-123, 2006.

[190] X. B. Ding, L. G. Feng, J. Xu et al., "Study on the prevalence of HIV, Syphilis, HCV and HSV-II and its associated factors among 743 men who have sex with men in Chongqing," Chinese Journal of Disease Control \& Prevention, vol. 14, no. 3, pp. 227231, 2010.

[191] H. Guo, J. Wei, H. Yang, X. Huan, S. K. Tsui, and C. Zhang, "Rapidly increasing prevalence of HIV and syphilis and HIV1 subtype characterization among men who have sex with men in Jiangsu, China," Sexually Transmitted Diseases, vol. 36, no. 2, pp. 120-125, 2009.

[192] Z. X. Lu, N. Ge, H. R. Gao, L. L. Yan, and W. X. Yu, "Investigation on AIDS related knowledge, behavior and infection among Men who Have Sex with Men (MSM) in Yancheng City from 2007 to 2008," Preventive Medicine Tribune, vol. 15, no. 8, pp. 702-703, 2009.

[193] Z. J. Wang, L. Sun, and X. J. Ma, "Survey on AIDS/STD risk behaviors and prevalence among men who have sex with men in Guangling, Yangzhou," Jiangsu Journal of Preventive Medicine, vol. 21, no. 2, pp. 4-7, 2010.

[194] X. Chen, C. Zhu, and H. Lu, "Study on HIV/AIDS-related knwoledge and awareness among men who have sex with men," Shanghai Journal of Preventive Medicine, vol. 23, no. 10, pp. 478479, 2011.

[195] X. Huan, C. Hao, H. Yan et al., "High prevalence of HIV and syphilis among men who have sex with men recruited by respondent-driven sampling in a City in Eastern China," AsiaPacific Journal of Public Health, 2013.

[196] X. Chen, Y. Y. Zhu, X. P. Hai et al., "Comparison of HIV/AIDS prevalence among men who have sex with men between Suzhou and Yangzhou City," Chinese Journal of Public Health, vol. 28, no. 12, pp. 1549-1552, 2012.

[197] X. P. Huan, X. Chen, H. J. Yan et al., "Analysis of the high risk behaviors, HIV infection and related factors among men who have sex with men in Yangzhou," Chinese Journal of Health Statistics, vol. 29, no. 2, pp. 202-205, 2012.

[198] J. B. Zhou, C. Hao, X. P. Huan et al., "HIV and syphilis infections among men who have sex with men," Chinese Journal of Public Health, vol. 28, no. 8, pp. 1031-1035, 2012.

[199] S. L. Ning, Y. X. Lai, and H. Y. Chen, "The intervention model of men who have sex with men in Nanjing, Qinhuai District," China Modern Doctor, vol. 50, no. 23, pp. 104-106, 2012.

[200] P. Liu, C. N. Xiao, M. Q. Shi, J. P. Zhang, J. Jiang, and J. F. Sun, "Prevalence of sexually transmitted diseases among men who have sex with men in some cities of Jiangsu Province," Chinese Journal of Dermatology, vol. 46, no. 9, pp. 626-629, 2013.

[201] M. Zhang, H. J. Yan, S. S. Wu, and L. Liu, "Influence factor analysis on not having HIV test among men who have sex with men," Jiangsu Journal of Preventive Medicine, vol. 23, no. 5, pp. 15-17, 2012.

[202] Y. L. Guo, J. B. Zhou, C. Hao et al., "Comparative analysis on both high risk behaviours, infection of HIV and syphilis between married and unmarried men who have sex with men," Zhonghua Liu Xing Bing Xue Za Zhi, vol. 34, no. 1, pp. 19-23, 2013.

[203] Y. B. Xu, X. Zhang, Z. K. Zhu, L. Pan, and M. R. Yu, "Study on HIV infection among men who have sex with men in Taizhou City of Jiangsu Province," Jiangsu Journal of Preventive Medicine, vol. 23, no. 5, pp. 50-51, 2012.
[204] M. H. Zhang, X. X. Liu, X. Chen et al., "Baseline survey from cohort study among MSM in Zhenjiang City in 2010," Occupation and Health, vol. 28, no. 18, pp. 2197-2201, 2012.

[205] L. Xiao, B. Wang, J. Wang, and W. X. Yu, "Investigation on HIV, syphilis and HCV infection among men who have sex with men in Yancheng City of Jiangsu Province," Journal of Dermatology and Venereology, vol. 35, no. 2, pp. 112-113, 118, 2013.

[206] Y. X. Zhu, W. H. Guan, Q. Wei, X. G. Wu, and L. P. Chen, "Analysis on condom usage among 217 men who have sex with men who received voluntary counseling and testing (VCT)," Jiangsu Journal of Preventive Medicine, vol. 24, no. 3, pp. 33-34, 2013.

[207] L. Lu, D. Xu, H. H. Qiu et al., "Investigation on STDs/AIDS infection among MSM in Nanchang," Journal of Public Health and Preventive Medicine, vol. 22, no. 1, pp. 45-46, 2011.

[208] W. Huang, Y. Xiao, X. Yang et al., "Survey on HIV/STD infection and the related knowledge and behavior among 260 MSM in Jiujiang City," Practical Preventive Medicine, vol. 18, no. 12, pp. 2275-2277, 2011.

[209] J. Hu, Y. Wang, and J. Li, "Prevalence of HIV, syphilis, hepatitis C and associated high-risk behaviours among men who have sex with men in Donghu District of Nanchang City," World Health Digest Medical Periodical, vol. 8, no. 17, pp. 68-69, 2011.

[210] L. Deng, Y. S. Chen, J. H. Zhu et al., "Sentinel surveillance of HIV, syphilis and HCV infection among men who have sex with men in Pingxiang City of Jiangxi Province, 2009-2011," Medical Information, vol. 26, no. 13, p. 78, 2013.

[211] X. J. Xu, X. Qin, X. H. Wang, Z. M. Liu, and Z. Hu, "Analysis on the participation of NGO in HIV/AIDS prevention and control in China," Quality Control of Diseases Prevention, vol. 16, no. 6, pp. 67-69, 2009.

[212] M. L. Sun, D. J. Li, W. Jin, J. Jiang, and L. Guan, "Investigation on the infection of HIV, HCV, syphilis and HBV among MSM in Dalian City in 2008," Preventive Medicine Tribune, vol. 15, no. 11, pp. 1074-1075, 2009.

[213] J. X. Wang, W. Dong, R. Li, Z. Zhao, B. Xiong, and J. Gang, "A survey of HIV/STD infection and behaviors among MSM," Chinese Journal of Public Health, vol. 20, no. 11, pp. 1377-1378, 2004.

[214] R. Li, W. Tong, Z. J. Zhao, X. H. Jiang, and X. H. Zhang, "Analysis on the surveillance results and epidemiological characteristics of HIV/AIDS in Dalian," Disease Surveillance, vol. 24, no. 11, pp. 852-855, 2009.

[215] Y. Gu, P. Qu, L. Xu et al., "Survey of knowledge, attitude, behavior and practice related to STI/HIV among male homosexuality in Shenyang," Chinese Journal of Public Health, vol. 20, no. 5, pp. 573-574, 2004.

[216] J. Xu, M. Zhang, K. Brown et al., "Syphilis and HIV seroconversion among a 12-month prospective cohort of men who have sex with men in Shenyang, China," Sexually Transmitted Diseases, vol. 37, no. 7, pp. 432-439, 2010.

[217] J. Xu, K. H. Reilly, C. Lu et al., "A cross-sectional study of HIV and syphilis infections among male students who have sex with men (MSM) in northeast China: implications for implementing HIV screening and intervention programs," BMC Public Health, vol. 11, no. 1, article 287, 2011.

[218] L. D. Li, W. B. Zhao, and Y. F. Jiang, "Study on HIV/AIDS infection and associated factors among men who have sex with men in Anshan, Liaoning Province," Chinese Medical Journal of Metallurgical Industry, vol. 27, no. 6, pp. 684-685, 2010. 
[219] G. Q. Lin, Y. Chen, C. Chen, and B. Jiang, "Investigation on Knowledge, Attitude and Practice among MSM in Benxi City," Occupation and Health, vol. 27, no. 5, pp. 532-534, 2011.

[220] L. Zhao, W. B. Zhao, B. Zheng, and T. H. Yan, "Investigation on knowledge, attitude and behaviors of HIV/AIDS, and health needs among men who have sex with men in Anshan City of Liaoning Province," Chinese Journal of Public Health, vol. 28, no. 9, pp. 1230-1231, 2012.

[221] J. L. Zhou, Y. Zhang, J. P. Shi, and L. Wang, "Knowledge and behavior about HIV/AIDS and HIV infection among MSM in Liaoning Province," Chinese Journal of Public Health, vol. 28, no. 6, pp. 806-808, 2012.

[222] X. Wang, "Knowledge of HIV/AIDS, and prevalence of HIV and syphilis among men who have sex with men in Fushun City of Liaoning Province in 2011," Journal of China Traditional Chinese Medicine Information, vol. 4, no. 4, pp. 481-482, 2012.

[223] G. Q. Lin and B. L. Fang, "Investigation on HIV and syphilis infection among MSM people in Benxi City," Occupation and Health, vol. 29, no. 6, pp. 2-3, 2013.

[224] Z. F. Miao, J. Li, L. M. Lei, X. Han, and X. P. Zhang, "Survey of AIDS-related knowledge and behavior in 312 MSM," Journal of Ningxia Medical University, vol. 31, no. 6, pp. 761-762, 2009.

[225] Z. F. Miao, F. Jiang, X. Han, and Z. G. Yang, "An investigation of knowledge and infection status on syphilis and AIDS in MSM population in Yinchuan," Journal of Ningxia Medical University, vol. 34, no. 9, pp. 910-911, 914, 2012.

[226] H. R. Zhang, "A study on HIV prevalence among men who have sex with men in Xining District of Qinghai Province," Modern Preventive Medicine, vol. 39, no. 15, p. 3907, 2012.

[227] S. X. He and H. D. Zhang, "Analysis on demographic characteristics and HIV/STD infection among men who have sex with men in Golmud City of Qinghai Province," Qinghai Medical Journal, vol. 42, no. 4, pp. 87-88, 2012.

[228] X. Li, A. H. Xing, W. H. Chang et al., "Analysis on AIDS surveillance on MSM in Xi'an, 2003-2008," Chinese Journal of Disease Control and Prevention, vol. 13, no. 4, pp. 442-444, 2009.

[229] X. Li, A. H. Xing, B. S. Wang et al., "Analysis of AIDS surveillance data in Shaanxi Province in 2005," Chinese Journal of AIDS \& STD, vol. 13, no. 2, pp. 137-138, 155, 2007.

[230] W. H. Chang, A. H. Xing, B. S. Wang et al., "Results of sentinel surveillance among MSM in Shaanxi Province from 2007-2011," Occupation and Health, vol. 29, no. 9, pp. 1058-1061, 2013.

[231] W. H. Chang, A. H. Xing, B. S. Wang et al., "Analysis of HIV/AIDS sentinel surveillance among high risk population in Shaanxi in 2010," Occupation and Health, vol. 28, no. 4, pp. 399402, 2012.

[232] S. Ruan, H. Yang, Y. Zhu et al., "HIV prevalence and correlates of unprotected anal intercourse among men who have sex with men, Jinan, China," AIDS and Behavior, vol. 12, no. 3, pp. 469475, 2008.

[233] S. Ruan, H. Yang, Y. Zhu et al., "Rising HIV prevalence among married and unmarried among men who have sex with men: Jinan, China," AIDS and Behavior, vol. 13, no. 4, pp. 671-676, 2009.

[234] M. Z. Liao, X. Z. Liu, J. H. Fu, Y. S. Qian, and X. F. Zhang, "Analysis of data of behavioral surveillance in men who have sex with men (MSM) in Shandong Province," Chinese Journal of AIDS \& STD, vol. 12, no. 6, pp. 530-532, 2006.

[235] X. Cai, "The analysis of risk behaviors of MSM in Liaocheng and the serological detection for Anti-HIV, Anti-TP, and Anti-HCV antibodies in 2006," Preventive Medicine Tribune, vol. 13, no. 10, pp. 888-890, 2007.
[236] Y. W. Zhu, S. M. Ruan, H. Yang et al., "Investigation on AIDS related knowledge risk behavior and HIV infection in MSM in Ji'nan City," Preventive Medicine Tribune, vol. 13, no. 6, pp. 490492, 2007.

[237] X. Y. Han, L. Z. Liu, W. Zhang et al., "Investigation on the related nosogenic infection among 635 men who have sex with men in Jinan," Preventive Medicine Tribune, vol. 13, no. 12, pp. 10911092, 2007.

[238] S. M. Jiang, J. Z. Li, R. Y. Li, H. J. Zhang, and H. C. Xiao, "Investigation on unprotected sex and AIDS knowledge among men who have sex with men in Weihai City," Preventive Medicine Tribune, vol. 12, no. 6, pp. 763-764, 2006.

[239] M. Z. Liao, X. Z. Liu, J. H. Fu, Y. S. Qian, and T. Z. Wang, "Analysis of HIV/AIDS surveillance data in Shandong Province in 2007," Preventive Medicine Tribune, vol. 14, no. 12, pp. 11431145, 2008.

[240] L. G. Feng, X. B. Ding, R. R. Lu et al., "Trend on prevalence of HlV and syphilis and estimated HIV incidence among young male students who have sex with men," Acta Academiae Medicinae Militaris Tertiae, vol. 32, no. 24, pp. 2644-2646, 2010.

[241] H. Y. Shu, Y. Q. Zhang, Z. C. Li, D. Y. Liu, and X. T. Li, "HIV, syphilis infection among high-risk population in Zoucheng City of China," Chinese Rural Health Service Administration, vol. 30, no. 3, pp. 211-213, 2010.

[242] C. Q. Zhang, S. M. Ruan, Z. L. Shi et al., "Survey of HIV/AIDS related knowledge and behavior among high-risk population in Jinan City," Chinese Journal of AIDS \& STD, vol. 14, no. 1, pp. 55-57, 2008.

[243] X. X. Sun, "Knowledge, attitude and behavior of HIV/AIDS among 143 homosexual men in Yantai City of Shandong Province," Seek Medical and Ask the Medicine, vol. 10, no. 4, pp. 713-714, 2012.

[244] S. Yang, X. S. Cheng, J. J. Jiang, R. Lin, and M. B. Wang, "Study on the high risk behavioral change and related factors among MSM in Yantai City, 2009-2011," Chinese Journal of Disease Control \& Prevention, vol. 17, no. 8, pp. 666-669, 2013.

[245] Y. X. Wang, D. M. Kang, M. Z. Liao et al., "Condom use and its influence factors among men who have sex with men in Shandong Province," Chinese Journal of Public Health, vol. 28, no. 11, pp. 1442-1445, 2012.

[246] Y. W. Zhu, S. M. Ruan, Y. X. Hu et al., "Prevalence of HIV infection and syphilis among men who have sex with men in different places in Jinan," Disease Surveillance, vol. 27, no. 8, pp. 631-633, 659, 2012.

[247] Y. F. Li, J. Xu, and P. Li, "Comparative studies on HIV infection and related knowledge-based behavior between normal MSM group and MB group," Chinese Journal of Behavioral Medicine and Brain Science, vol. 21, no. 4, pp. 346-348, 2012.

[248] J. Wu, L. Chen, H. L. Fan, and Y. Ruan, "A survey on the prevalence of HIV-1 and syphilis infection and characteristics of sexual behaviors in MSM, (men who have sex with men) living in Shanghai," Journal of Diagnostics Concepts \& Practice, vol. 7, no. 3, pp. 296-299, 2008.

[249] K. Choi, Z. Ning, S. E. Gregorich, and Q. Pan, "The influence of social and sexual networks in the spread of HIV and syphilis among men who have sex with men in Shanghai, China," Journal of Acquired Immune Deficiency Syndromes, vol. 45, no. 1, pp. 77-84, 2007.

[250] X. Zhang, J. Zhou, X. Huang et al., "Investigation of HIV infection and sex behaviors among MSM in Pudong District, 2008-2012," Medicine and Society, vol. 26, no. 5, pp. 51-52, 2013. 
[251] Y. Q. Zhou, J. Gao, K. K. Gu, H. Wang, and X. L. Ma, “Testing of HIV and syphilis and investigation and risk factors among 416 MSM," Chinese Primary Health Care, vol. 26, no. 11, pp. 72-74, 2012.

[252] Z. B. Xuan, H. M. Huang, Y. Hou et al., "Sexual characteristics and HIV and syphilis infections among 98 MSM in Yangpu District, Shanghai," Chinese Journal of Disease Control \& Prevention, vol. 16, no. 12, pp. 1028-1031, 2012.

[253] J. Wang and J. Z. Zheng, "Investigation on the behavior of MSM in Taiyuan City," Journal of Shanxi Medical University, vol. 40, no. 12, pp. 1088-1090, 2009.

[254] L. Mei, H. Han, and X. Che, "A survey of the first round AIDS integrate controlling work trial spot among men who have sex with man in Taiyuan," Chinese Journal of Epidemiology, vol. 30, no. 6, pp. 649-650, 2009.

[255] H. Han, L. Mei, X. W. Che, Q. Y. Zhao, and T. Han, "Sentinel surveillance of AIDS among men who have sex with men in Taiyuan, Shanxi, 2012," Disease Surveillance, vol. 27, no. 12, pp. 964-966, 2012.

[256] Y. Feng, Z. Wu, R. Detels et al., "HIV/STD prevalence among men who have sex with men in Chengdu, China and associated risk factors for HIV infection," Journal of Acquired Immune Deficiency Syndromes, vol. 53, supplement 1, pp. S74-S80, 2010.

[257] Q. He, X. Wu, D. Han, and X. Liang, "HIV infection and risk behavior of men having sex with men in Chengdu City from 2004 to 2007," Journal of Occupational Health and Damage, vol. 23, no. 4, pp. 222-224, 2008.

[258] Q. P. Zhang, X. B. Ding, L. G. Feng et al., "Analysis on HIV and syphilis infection among male sex workers," Acta Academiae Medicinae Militaris Tertiae, vol. 33, no. 3, pp. 318-320, 2011.

[259] D. L. Han, X. D. Wang, X. Liang et al., "Comparative study on AIDS related knowledge, attitude and behavior among MSM in different places of Chengdu City," Modern Preventive Medicine, vol. 36, no. 15, pp. 2910-2912, 2915, 2009.

[260] H. H. Zhu, Q. Y. He, Y. Liu, Q. Zhang, and D. L. Han, "Analysis on surveillance results of HIV in Chengdu in 2009," Practical Preventive Medicine, vol. 17, no. 10, pp. 1991-1992, 1998, 2010.

[261] Y. W. Duan, H. B. Zhang, X. D. Wang, Y. Wang, H. Y. Jiang, and J. Wang, "Survey on HIV related risk factors among MSM in Mianyang and Yibin," Chinese Journal of Disease Control and Prevention, vol. 14, no. 12, pp. 1189-1192, 2010.

[262] W. Yi, J. Xu, Z. J. Li et al., "Analysis on HIV/syphilis infection with queue baseline of MSM and the influencing factors in Mianyang City," The Chinese Journal of Dermatovenereology, vol. 26, no. 5, pp. 410-414, 2012.

[263] Q. Li and X. Chen, "Analysis of AIDS sentinel surveillance among MSM in Zigong from 2008 to 2010," Modern Preventive Medicine, vol. 39, no. 12, pp. 3108-3110, 2012.

[264] S. Zhou, X. H. Zhao, and J. He, "HIV/AIDS sentinel surveillance among men who have sex with men in Mianyang, 2010," Journal of Preventive Medicine Information, vol. 28, no. 3, pp. 171-174, 2012.

[265] B. L. Chen, P. Zhu, L. Liu, D. C. Chen, and N. Zhong, "Studying on monitoring results and solution of special populations about HIV, syphilis and hepatitis C infections in Da'an District," The Chinese Health Service Management, vol. 29, no. 10, pp. 798-799, 2012.

[266] M. Tang, "Analysis of sexual behaviors and related infection status among men who have sex with men in Dazhou City of Sichuan Province," Journal of Occupational Health and Damage, vol. 27, no. 5, pp. 314-315, 2012.
[267] W. H. Jiang, Q. Y. He, and S. F. Fan, "Status and risk factors of HIV infection among MSM in Chengdu," Journal of Preventive Medicine Information, vol. 29, no. 1, pp. 36-40, 2013.

[268] Q. L. Huang, L. M. Dong, F. F. Yoo, and Y. Xie, "Study on influence factors about HIV infection and high risk behavior among men who have sex with men," Modern Medicine Journal of China, vol. 14, no. 6, pp. 7-10, 2012.

[269] J. Ma and J. Guo, "Internet survey of high risk sexual behaviors and sexually transmitted diseases among male homosexuals in Tianjin," Modern Preventive Medicine, vol. 34, no. 20, pp. 39283931, 2007.

[270] Y. Guo, X. K. Zhu, J. H. Xia, and X. Y. Dong, "Study on $\mathrm{HIV} /$ syphilis infections among men who have sex with men and their behavioral feature," Chinese Journal of AIDS \& STD, vol. 15, no. 1, pp. 50-51, 71, 2009.

[271] G. H. Wei and H. Y. Gao, "Results of HIV antibody detection among high-risk population in Tanggu area of Tianjin during 2007-2009," Occupation and Health, vol. 27, no. 5, pp. 550-551, 2011.

[272] T. L. Ning, Y. Guo, Z. Q. Liu et al., "Survey on recent infection of human immunodeficiency virus among men who have sex with men in Tianjin during 2008-2009," Zhonghua Liu Xing Bing Xue Za Zhi, vol. 32, no. 11, pp. 1087-1090, 2011.

[273] S. H. Cheng, X. D. Wang, Y. Y. Zheng, Y. Y. Gao, X. K. Zhu, and X. P. Nie, "Practices and experience of implementing voluntary counseling and testing among the gay community in Tianjin City," Chinese Journal of AIDS \& STD, vol. 17, no. 5, pp. 591-592, 2011.

[274] T. L. Ning, Y. Guo, Z. Q. Liu, S. H. Cheng, Y. Jiang, and X. J. Zhang, "Epidemic analysis of HIV-1 incidence using BEDCEIA assay in Tianjin, China, 2010," National Medical Journal of China, vol. 93, no. 13, pp. 1020-1022, 2013.

[275] Y. G. Ma and X. Ya, "Investigation on status of HIV infection and high-risk behaviors among who have sex with men in some cities of Tibet," Chinese Journal of Social Medicine, vol. 27, no. 4, pp. 254-255, 2010.

[276] S. J. Yang, H. T. Mu, X. Q. Li et al., "Survey of the knowledge, attitude, and practice on AIDS among MSM population in Urumchi," Modern Preventive Medicine, vol. 34, no. 20, pp. 4624-4625, 2007.

[277] S. P. Yang, S. R. Wang, J. Y. Wang, R. F. Wang, Y. T. Ayeti, and L. M. Ke, "Investigation on AIDS knowledge and behaviors among men who have sex with men in Hami prefecture," Endemic Disease Bulletin, vol. 23, no. 5, pp. 49-50, 2008.

[278] M. Zhang, X. D. Wang, and Y. Yang, "Prevalence oh HIV, anti$\mathrm{HCV}$, syphilis infection and AIDS knowledge among men who have sex with men (MSM) in Urumqi," Chinese Journal of Public Health, vol. 25, no. 9, pp. 1075-1076, 2009.

[279] Y. Zhang, J. W. Liu, M. J. Ni, and Y. H. Dong, "Laboratory study on detective results of male homosexuality population in Urumqi, Xinjiang," Endemic Disease Bulletin, vol. 23, no. 2, pp. 26-28, 2008.

[280] X. Wang, Y. Ma, and Y. Yang, "Prevalence of HIV, syphilis and $\mathrm{HCV}$ among men who have sex with men in Urumqi City of Xinjiang Uyghur Autonomous Region," Journal of Dermatology and Venereology, vol. 33, no. 2, pp. 104-105, 2011.

[281] M. Zhang, B. L. Rui, Y. X. Wang, and Y. Yang, "Investigation on HIV infection and related behaviors among high risk population in Urumqi," Occupation and Health, vol. 29, no. 4, pp. 477-478, 480, 2013. 
[282] A. B. Ma, X. J. An, H. F. Yu et al., "HIV seropositivity in 78 MSM from Yunnan Province in 2005," Chinese Journal of AIDS \& STD, vol. 13, no. 1, pp. 60-61, 2007.

[283] J. M. Zhang, "Analysis on health status among 110 men who have sex with men in Jianshui county, Yunnan Province," Health World, vol. 4, no. 11, pp. 37-38, 2010.

[284] L. M. Gao, L. Chen, Y. Ma, J. B. Lu, L. X. Li, and Y. L. Zhang, "HIV/STD infection and KABP status among men who have sex with men in Yuxi City, Yunnan Province, 2009-2010," Soft Science of Health, vol. 24, no. 6, pp. 547-549, 553, 2010.

[285] Z. Li, Y. Z. Wang, Z. L. Wang, Y. Lu, and L. H. Lei, "An analysis of 490 HIV-infected MSMs in Kunming," Journal of Kunming Medical University, vol. 10, no. 31, pp. 127-129, 2010.

[286] H. Chen, W. Luo, Y. Li, and Z. Lo, "Analysis on HIV and syphilis infection among 831 men who have sex with men," Journal of Dermatology and Venereology, vol. 33, no. 4, pp. 236-237, 2011.

[287] Z. Chen, X. M. Chen, L. H. Huang et al., "Sentinel surveillance among men who have sex with men in Dali prefecture of Yunnan Province in 2010," Soft Science of Health, vol. 25, no. 10, pp. 719-720, 728, 2011.

[288] G. Z. Yang, H. Wang, and J. C. Shi, "Survey of HIV/TP infection of gay men in Dali prefecture," Chinese Journal of Health Laboratory Technology, vol. 21, no. 4, pp. 995-996, 2011.

[289] E. P. Chow, L. Chen, J. Jing et al., "HIV disease burden and related risk behaviours among men who have sex with men in Yuxi prefecture, Yunnan Province, China: 2010-2011," AIDS and Behavior, vol. 17, no. 7, pp. 2387-2394, 2013.

[290] H. B. Luo, J. Y. Mei, L. J. Song et al., "A comprehensive surveillance on HIV among 1237 men who have sex with men in thirteen cities of Yunnan," Zhonghua Liu Xing Bing Xue Za Zhi, vol. 33, no. 7, pp. 706-709, 2012.

[291] D. L. Li, Q. C. Li, S. M. Li et al., "Attitude toward circumcision for prevention of HIV infection among men who have sex with men," Chinese Journal of Public Health, vol. 26, no. 6, pp. 728729, 2010.

[292] G. F. Cai, Q. Q. Ma, X. H. Pan et al., "HIV/AIDS related knowledge, attitude, practice and HIV/STD infection among MSM in two cities of Zhejiang Province," China Preventive Medicine, vol. 9, no. 6, pp. 482-485, 2008.

[293] J. F. Feng, H. J. Lin, Y. F. Zhang, D. H. Qiu, Q. H. Wu, and W. W. Shen, "Investigation on the related knowledge, behavior and infection of HIV/Syphilis among men who have sex with men in Taizhou City," Shanghai Journal of Preventive Medicine, vol. 20, no. 11, pp. 531-533, 541, 2008.

[294] F. H. Xue, S. Z. Xia, S. F. Lin, Y. H. Jin, H. S. Zhu, and M. Q. Wen, "Survey on high risk behaviors and HIV/STD infection status among men who have sex with men," Disease Surveillance, vol. 25, no. 1, pp. 54-56, 2010.

[295] L. J. Fu, Y. R. Fang, and T. Y. Guo, "Investigation of the sexual behaviors among the MSM in Shaoxing City of Zhejiang Province," Disease Surveillance, vol. 22, no. 12, pp. 818-819, 2007.

[296] S. J. Xi, Y. F. He, and X. H. Zhou, "Analysis on the result of AIDS test intervention in CSW, MSM, IDU population in Xiacheng District," Zhejiang Preventive Medicine, vol. 22, no. 9, pp. 29-30, 2010.

[297] J. F. Feng and H. J. Lin, "Analysis of HIV/AIDS epidemic in Taizhou, Zhejiang Province, 1996-2007," China Preventive Medicine, vol. 10, no. 4, pp. 284-287, 2009.

[298] R. Zhang, H. Q. Shuai, and X. C. Shang, "Investigation on the infection of HIV and sex transmitted diseases in the man who have sex with man from 2006 to 2009 in Hangzhou," Chinese
Journal of Health Laboratory Technology, vol. 21, no. 3, pp. 732733, 2011.

[299] Z. H. Guo, Y. Xu, Y. Xia et al., "Estimation of new HIV-1 infection in high risk groups with BED-CEIA in Zhejiang, 20102012," Disease Surveillance, vol. 28, no. 8, pp. 617-620, 2013.

[300] J. J. Ruan, B. X. Zhu, and D. J. Jia, "Analysis of sexual behaviors and prevalence of sexually transmitted infections among men who have sex with men in Yiwu City of Zhejiang Province," Shanghai Journal of Preventive Medicine, vol. 24, no. 1, pp. 1819, 2012.

[301] Y. Zhang, D. D. Zhang, and H. Hong, "Dynamic analysis of prevalence of AIDS and high risk behaviors among men who have sex with men in Ningbo, 2010-2012," Disease Surveillance, vol. 28, no. 8, pp. 639-642, 2013.

[302] L. H. Wang, Y. Y. Xu, J. Weng et al., "Cross-sectional investigation on HIV prevalence and HIV related risk behavior among men who have sex with men in Taizhou, Zhejiang," Disease Surveillance, vol. 28, no. 5, pp. 362-365, 2013.

[303] X. Y. Luo and R. Q. Shi, "Knowledge, attitude and behaviors among 247 men who have sex with men," Zhejiang Journal of Preventive Medicine, vol. 25, no. 5, pp. 83-84, 2013.

[304] S. Li, X. Zhang, X. Li et al., "Detection of recent HIV-1 infections among men who have sex with men in Beijing during 20052006," Chinese Medical Journal, vol. 121, no. 12, pp. 1105-1108, 2008.

[305] D. Li, S. Li, Y. Liu et al., "HIV incidence among men who have sex with men in Beijing: a prospective cohort study," British Medical Journal Open, vol. 2, no. 6, Article ID e001829, 2012.

[306] M. Han, L. Feng, Y. Jiang et al., "Surveillance on HIV-1 incidence among men who have sex with men in Chongqing, China, 2006-2008," Zhonghua Liu Xing Bing Xue Za Zhi, vol. 30, no. 9, pp. 878-881, 2009.

[307] R. Z. Zhang, W. Y. Zhang, Y. F. Li et al., "A prospective cohort study on HIV incidence among men who have sex with men in Chongqing," Chinese Journal of Preventive Medicine, vol. 46, no. 10, pp. 955-957, 2012.

[308] M. Han, L. G. Feng, J. K. Zhao et al., "A survey of BED HIV-1 incidence among MSM in Chonqging of China, 2009," Chinese Journal of AIDS \& STD, vol. 17, no. 6, pp. 654-666, 2011.

[309] G. H. Lan, W. Liu, F. X. Liang, Y. M. Huang, and H. Liang, "Incidences of HIV, syphilis and HSV-2 among men who have sex with men in Nanning City: a follow-up study," Chinese Journal of Public Health, vol. 29, no. 2, pp. 175-178, 2013.

[310] S. Hui, Y. Li, J. Zhang, K. L. Wang, B. Meng, and X. Tong, "Application of BED-CEIA to estimate incidence of human immunodeficiency virus among men who have sex with men in Heilongjiang Province in 2011," Chinese Journal of Public Health Management, vol. 28, no. 4, pp. 399-400, 2012.

[311] W. G. Cui, J. Liu, Y. G. Nie et al., "Estimation of HIV type 1 incidence with BED-CEIA among high-risk populations in Henan, 2009," Zhongguo Bingdubing Zazhi, vol. 2, pp. 116-118, 2011.

[312] M. Zhang, H. J. Yan, N. Wang, S. S. Wu, and J. Q. Li, "Incidence of HIV infection, retention rate in a prospective cohort among men who have sex with men in Nanjing," Chinese Journal of Disease Control and Prevention, vol. 15, no. 10, pp. 839-842, 2011.

[313] H. Y. Hu, X. Q. Xu, G. F. Fu et al., "A survey of HIV-1 incidence of men who have sex with men in three cities of Jiangsu Province, 2008-2009," Acta Universitatis Medicinalis Nanjing (Natural Science), vol. 32, no. 4, pp. 487-490, 2012. 
[314] H. Y. Hu, H. X. Guo, G. F. Fu, X. Q. Xu, X. P. Huan, and H. T. Yang, "Application of pooled HIV-1 RNA RT-PCR in detecting HIV window period in MSM," Acta Universitatis Medicinalis Nanjing (Natural Science), vol. 29, no. 10, pp. 1395-1398, 2009.

[315] H. Y. Hu, S. Shen, X. P. Huan, H. J. Yan, Y. Xiao, and Y. Jiang, "Estimation of HIV-1 incidence of MSM in Jiangsu Province with BED-CEIA assay," Acta Universitatis Medicinalis Nanjing (Natural Science), vol. 30, no. 4, pp. 467-471, 2010.

[316] X. X. Liu, M. H. Zhang, X. Chen et al., "Analysis on the seroconversion of HIV/syphilis and the predictors of cohort retention among men who have sex with men in Zhejiang," Chinese Journal of Disease Control \& Prevention, vol. 16, no. 12, pp. 1024-1027, 2012.

[317] D. Z. Yang, Z. L. Wu, L. H. Zhao, and G. Y. Guan, "Estimation of HIV incidence of MSM with BED incidence capture enzyme immunoassay in Ningxia," Ningxia Medical Journal, vol. 34, no. 7, pp. 611-612, 2012.

[318] Q. Ren, A. H. Xing, W. H. Chang et al., "Estimation of HIV-1 incidence of three high-risk populations in Shaanxi with BEDCEIA, 2011," Journal of Modern Laboratory Medicine, vol. 27, no. 4, pp. 15-18, 2012.

[319] Y. Wang, G. G. Zhang, L. L. Li et al., "Analysis on the new $\mathrm{HIV} /$ syphilis infections of MSM in Mianyang and the influencing factors," The Chinese Journal of Dermatovenereology, vol. 26, no. 6, pp. 509-512, 2012.

[320] R. Z. Zhang, W. Y. Zhang, Y. F. Li et al., "HIV incidence in a cohort of men who have sex with men in Chongqing," Chinese Journal of Preventive Medicine, vol. 46, no. 10, pp. 955-957, 2012.

[321] L. Chen, X. H. Pan, G. F. Cai et al., "A study on influencing factors of regular repeated HIV testing among MSM in Zhejiang Province," Zhejiang Journal of Preventive Medicine, vol. 25, no. 1, pp. 1-4, 2013

[322] Y. Ruan, D. Li, X. Li et al., "Relationship between syphilis and HIV infections among men who have sex with men in Beijing, China," Sexually Transmitted Diseases, vol. 34, no. 8, pp. 592597, 2007.

[323] K. Choi, D. R. Gibson, L. Han, and Y. Guo, "High levels of unprotected sex with men and women among men who have sex with men: a potential bridge of HIV transmission in Beijing, China," AIDS Education and Prevention, vol. 16, no. 1, pp. 19-30, 2004.

[324] H. Liu, H. Yang, X. Li et al., "Men who have sex with men and human immunodeficiency virus/sexually transmitted disease control in China," Sexually Transmitted Diseases, vol. 33, no. 2, pp. 68-76, 2006.

[325] K. Choi, H. Liu, Y. Guo, L. Han, J. S. Mandel, and G. W. Rutherford, "Emerging HIV-1 epidemic in China in men who have sex with men," The Lancet, vol. 361, no. 9375, pp. 2125-2126, 2003.

[326] B. Zhang, D. Liu, X. Li, and T. Hu, "A survey of men who have sex with men: mainland China," The American Journal of Public Health, vol. 90, no. 12, pp. 1949-1950, 2000.

[327] A. B. Daniel, "Sex, singing, and civility: the costs and benefits of the Karaoke trade," in China's New Confucianism: Politics and Everyday Life in a Changing Society, pp. 59-74, Princeton University Press, Princeton, NJ, USA, 2010.

[328] N. He, F. Y. Wong, Z. J. Huang et al., "HIV risks among two types of male migrants in Shanghai, China: money boys vs. general male migrants," AIDS, vol. 21, supplement 8, pp. S73-S79, 2007.

[329] H. Liu, H. Liu, Y. Cai, A. G. Rhodes, and F. Hong, "Money boys, HIV risks, and the associations between norms and safer sex: a respondent-driven sampling study in Shenzhen, China," AIDS and Behavior, vol. 13, no. 4, pp. 652-662, 2009.

[330] S. J. Xi, Y. F. He, and X. H. Zhou, "Analysis of influencing factors of risk behaviors associated with AIDS among money boys in Hangzhou, Zhejiang," Disease Surveillance, vol. 24, no. 11, pp. 839-842, 2009.

[331] T. S. K. Kong, "Risk factors affecting condom use among male sex workers who serve men in China: a qualitative study," Sexually Transmitted Infections, vol. 84, no. 6, pp. 444-448, 2008.

[332] L. Zhang, E. P. Chow, H. J. Jahn, A. Kraemer, and D. P. Wilson, "High HIV prevalence and risk of infection among rural-to-urban migrants in various migration stages in China: a systematic review and meta-analysis," Sexually Transmitted Diseases, vol. 40, no. 2, pp. 136-147, 2013.

[333] J. Kaufman, "HIV, sex work, and civil society in China," The Journal of Infectious Diseases, vol. 204, supplement 5, pp. S1218S1222, 2011.

[334] X. Yang, "Temporary migration and the spread of STDs/HIV in China: is there a link?" International Migration Review, vol. 38, no. 1, pp. 212-235, 2004.

[335] L. Lu, M. Jia, Y. Ma et al., "The changing face of HIV in China," Nature, vol. 455, no. 7213, pp. 609-611, 2008.

[336] Ministry of Health People's Republic of China, "Joint United Nations Programme on HIV/AIDS," World Health Organization 2009 Estimates for the HIV/AIDS Epidemic in China, Beijing, China, 2010.

[337] Y. Wang, L. L. Li, J. Z. Fan et al., "Analysis on relationship of drug use behavior and HIV infection and related behaviors among men who have sex with men," Chinese Journal of Behavioral Medicine and Brain Science, vol. 22, no. 4, pp. 364-366, 2013.

[338] S. A. Strathdee and J. K. Stockman, "Epidemiology of HIV among injecting and non-injecting drug users: current trends and implications for interventions," Current HIV/AIDS Reports, vol. 7, no. 2, pp. 99-106, 2010.

[339] S. S. Bull, P. Piper, and C. Rietmeijer, "Men who have sex with men and also inject drugs-profiles of risk related to the synergy of sex and drug injection behaviors," Journal of Homosexuality, vol. 42, no. 3, pp. 31-51, 2002.

[340] F. Dikötter, "Crime and punishment in post-liberation China: the prisoners of a Beijing gaol in the 1950s," The China Quarterly, no. 149, pp. 147-159, 1997.

[341] X. Y. Long, "Foreign homosexual marriages and their adaptability in our country," Journal of Central South University (Social Science), vol. 18, no. 6, pp. 99-104, 2012.

[342] W. Yanhai, "Becoming a gay activist in contemporary China," Journal of Homosexuality, vol. 40, no. 3-4, pp. 47-64, 2001.

[343] T. Jacka, A. B. Kipnis, and S. Sargeson, "Community Institutions," in Contemporary China: Society and Social Change, pp. 83-104, Cambridge University Press, Port Melbourne, Australia, 2013.

[344] Psychiatric Department of Chinese Medical Association, Diagnostic Criteria of Mental Disorders (CCMD-3), Scientific and Technological Publishing House of Shandong, Jinan, China, 2001.

[345] X. Sun, N. Wang, D. Li et al., "The development of HIV/AIDS surveillance in China," AIDS, vol. 21, no. 8, pp. S33-S38, 2007.

[346] L. Wang, Z. W. Ding, R. X. Yan, D. M. Li, W. Guo, and N. Wang, "HIV prevalence among populations at risk, using sentinel surveillance data from 1995 to 2009 in China," Zhonghua Liu Xing Bing Xue Za Zhi, vol. 32, no. 1, pp. 20-24, 2011. 
[347] W. Lin, S. Chen, N. Seguy, Z. Chen, K. Sabin, J. G. Calleja et al., "Is the HIV sentinel surveillance system adequate in China? Findings from an evaluation of the national HIV sentinel surveillance system," Western Pacific Surveillance and Response Journal, vol. 3, no. 4, pp. 76-85, 2012.

[348] Y. Jia, F. Lu, X. Sun, and S. H. Vermund, "Sources of data for improved surveillance of HIV/AIDS in China," Southeast Asian Journal of Tropical Medicine and Public Health, vol. 38, no. 6, pp. 1041-1052, 2007.

[349] Y. Mao, Z. Wu, K. Poundstone et al., "Development of a unified web-based national HIV/AIDS information system in China," International Journal of Epidemiology, vol. 39, supplement 2, pp. ii79-ii89, 2010.

[350] L. Zhang, E. P. Chow, J. Zhang, J. Jing, and D. P. Wilson, "Describing the Chinese HIV surveillance system and the influences of political structures and social stigma," The Open AIDS Journal, vol. 6, pp. 163-168, 2012.

[351] Joint United Nations Programme on HIV/AIDS (UNAIDS), "Global report: UNAIDS report on the global AIDS epidemic 2012," UNAIDS, Geneva, Switzerland, 2012.

[352] M. Hvistendahl, "Public health. China partners with gay groups on HIV screening," Science (New York, N.Y.), vol. 339, no. 6115, pp. 17-18, 2013.

[353] Z. Wu, X. Sun, S. G. Sullivan, and R. Detels, "HIV testing in China," Science, vol. 312, no. 5779, pp. 1475-1476, 2006.

[354] Y. H. Hsieh, Y. Ruan, C. W. Chen, W. Shi, D. Li, F. Luo et al., "HIV prevalence and underreporting of men who have sex with men in Beijing," International Journal of STD \& AIDS, vol. 23, no. 8, pp. 606-607, 2012.

[355] Y. Song, X. Li, L. Zhang et al., "HIV-testing behavior among young migrant men who have sex with men (MSM) in Beijing, China," AIDS Care, vol. 23, no. 2, pp. 179-186, 2011.

[356] K. Choi, H. Lui, Y. Guo, L. Han, and J. S. Mandel, "Lack of HIV testing and awareness of HIV infection among men who have sex with men, Beijing, China," AIDS Education and Prevention, vol. 18, no. 1, pp. 33-43, 2006.

[357] Joint United Nations Programme on HIV/AIDS (UNAIDS), Marie Stopes International, the China Stigma Index Report, Institute of Social Development Research, China Central Part School, Beijing, China, 2009.

[358] X. Li, H. Lu, H. F. Raymond et al., "Untested and undiagnosed: barriers to HIV testing among men who have sex with men, Beijing, China," Sexually Transmitted Infections, vol. 88, no. 3, pp. 187-193, 2012.

[359] UN Technical Working Group on MSM and HIV/AIDS, "Enabling effective voluntary counselling and testing for men who have sex with men: increasing the role of community based organizations in scaling up VCT services for MSM in China," in United Nations Development Program in China, World Health Organization, Beijing, China, 2008.

[360] Z. Y. Chen, M. Wang, H. F. Xu, and W. Q. Chen, "Internet behavior and intention of internet-based intervention targeted to HIV high risk behaviors among MSM," South China Journal of Preventive Medicine, vol. 37, no. 3, pp. 23-26, 2011.

[361] B. C. Zhang and Q. S. Chu, "MSM and HIV/AIDS in China," Cell Research, vol. 15, no. 11-12, pp. 858-864, 2005.

[362] B. Zhang, X. Li, T. Hu, D. Liu, and N. Cao, "Friend communication' program-an effective AIDS intervention program for MSM," Chinese Journal of Health Education, vol. 17, no. 4, pp. 206-210, 2001.

[363] L. D. Wang, Zhongguo Aizibing Liuxing Yu Kongzhi, Beijing Publishing House, Beijing, China, 1st edition, 2006.
[364] G. Misra and R. Chandiramani, Sexuality, Gender and Rights: Exploring Theory and Practice in South and Southeast Asia, Sage, New Delhi, India, 2005.

[365] N. Jiang, Y. Xiao, M. Luo, and L. P. Cai, "Involvement of NGOs in AIDS global fund programs," Chinese Journal of AIDS \& STD, vol. 16, no. 3, pp. 300-302, 2010.

[366] H. Li, N. T. Kuo, H. Liu et al., "From spectators to implementers: civil society organizations involved in AIDS programmes in China," International Journal of Epidemiology, vol. 39, supplement 2, pp. ii65-ii71, 2010.

[367] S. Q. Huang and M. Luo, "Discussion on the HIV/AIDS prevention programs and grassroots organization," Chinese Journal of AIDS \& STD, vol. 13, no. 4, pp. 363-365, 2007.

[368] X. H. Zhang, "Utilitarianism and absence of trust: the reflection on utilitarianism guide in the movement of preventing and curing AIDS," in Medicine \& Philosophy: Humanistic \& Social Medicine Edition, vol. 29, no. 8, pp. 43-45, 2008.

[369] World Health Organization Regional Office for the Western Pacific, United nations Development Programme, Joint United Nations Programme on HIV/AIDS, Department of Health Hong Kong, Health sector response to HIV/AIDS among men who have sex with men in, Hong Kong, 2009.

[370] Key Laboratory of Immunology of AIDS, The First Hospital of China Medical University, "Analysis in the characteristics and trends of HIV/AIDS epidemics among men who have sex with men in seven cities of China in 2010," http://www.chain.net.cn/ document/20100416135855247897.ppt.

[371] K. H. Mayer, L. G. Bekker, R. Stall, A. E. Grulich, G. Colfax, and J. R. Lama, "Comprehensive clinical care for men who have sex with men: an integrated approach," The Lancet, vol. 380, no. 9839, pp. 378-387, 2012.

[372] Q. X. Su, F. Zhou, X. B. Tian, K. L. Zhang, and Z. L. Wu, "Capacity of non-governmental organizations of men who have sex with men at grassroots involving in HIV/AIDS prevention and control," Chinese Journal of Disease Control \& Prevention, vol. 14, no. 4, pp. 296-299, 2010.

[373] P. Ho and R. Edmonds, China's Embedded Activism: Opportunities and Constraints of a Social Movement, Routledge, London, UK, 2008.

[374] H. Li, M. Luo, J. F. Li et al., "Situation analysis for NGOs and civil societies involved in HIV/AIDS prevention and control programs in some provinces of China," Chinese Journal of AIDS \& STD, vol. 14, no. 3, pp. 246-248, 2008.

[375] E. P. F. Chow, D. P. Wilson, and L. Zhang, "The rate of HIV testing is increasing among men who have sex with men in China," HIV Medicine, vol. 13, no. 5, pp. 255-263, 2012.

[376] L. Wang, "Overview of the HIV/AIDS epidemic, scientific research and government responses in China," AIDS, vol. 21, supplement 8, pp. S3-S7, 2007.

[377] J. Qiu, "China: stigma of HIV imperils hard-won strides in saving lives," Science, vol. 332, no. 6035, pp. 1253-1254, 2011.

[378] The Joint United Nations Programme on HIV/AIDS (UNAIDS), "UNAIDS applauds China's decision to fill its HIV resource gap," 2013, http://www.unaids.org/en/resources/ presscentre/pressreleaseandstatementarchive/2011/december/ 20111201pschina/.

[379] P. Y. Ming, W. Su, J. X. Zhang et al., "Research of the capacity status in AIDS prevention and control for MSM communitybased organizations (CBO) in Chengdu City," Modern Preventive Medicine, vol. 39, no. 23, pp. 6281-6284, 6287, 2012. 
[380] Y. Liu, L. P. Cai, C. R. Jin et al., "A survey of MSM organizations' involvement in China's AIDS prevention and control," Chinese Journal of AIDS \& STD, vol. 16, no. 3, pp. 265-268, 2010.

[381] S. Q. Huang, C. E. Zeng, and M. Luo, "Difficulties and strategies research in grassroots organizations at AIDS prevention work," Chinese Journal of Pest Control, vol. 26, no. 10, pp. 909-910, 2010.

[382] R. C. Bailey, S. Moses, C. B. Parker et al., "Male circumcision for HIV prevention in young men in Kisumu, Kenya: a randomised controlled trial," The Lancet, vol. 369, no. 9562, pp. 643-656, 2007.

[383] B. Auvert, J. Sobngwi-Tambekou, E. Cutler et al., "Effect of male circumcision on the prevalence of high-risk human papillomavirus in young men: results of a randomized controlled trial conducted in orange farm, South Africa," Journal of Infectious Diseases, vol. 199, no. 1, pp. 14-19, 2009.

[384] R. H. Gray, G. Kigozi, D. Serwadda et al., "Male circumcision for HIV prevention in men in Rakai, Uganda: a randomised trial," The Lancet, vol. 369, no. 9562, pp. 657-666, 2007.

[385] K. Ben, J. Xu, L. Lu et al., "Male circumcision is an effective "surgical vaccine" for HIV prevention and reproductive health," National Journal of Andrology, vol. 15, no. 5, pp. 395-402, 2009.

[386] J. T. Lau, H. Yan, C. Lin et al., "How willing are men who have sex with men in China to be circumcised for the sake of protecting his female sex partner?" The Journal of Sexual Medicine, vol. 9, no. 7, pp. 1904-1912, 2012.

[387] J. T. F. Lau, J. Zhang, H. Yan et al., "Acceptability of circumcision as a means of HIV prevention among men who have sex with men in China," AIDS Care, vol. 23, no. 11, pp. 1472-1482, 2011.

[388] R. M. Grant, J. R. Lama, P. L. Anderson et al., "Preexposure chemoprophylaxis for HIV prevention in men who have sex with men," The New England Journal of Medicine, vol. 363, no. 27, pp. 2587-2599, 2010.

[389] F. Zhou, L. Gao, S. Li et al., "Willingness to accept hiv preexposure prophylaxis among chinese men who have sex with men," PLoS ONE, vol. 7, no. 3, Article ID e32329, 2012.

[390] Y. Zhang, B. Peng, Y. She et al., "Attitudes toward HIV preexposure prophylaxis among men who have sex with men in western China," AIDS Patient Care and STDs, vol. 27, no. 3, pp. 137-141, 2013.

[391] H. Zou, Z. Wu, J. Yu et al., "Internet-facilitated, voluntary counseling and testing (VCT) clinic-based HIV testing among men who have sex with men in China," PLoS ONE, vol. 8, no. 2, Article ID e51919, 2013. 


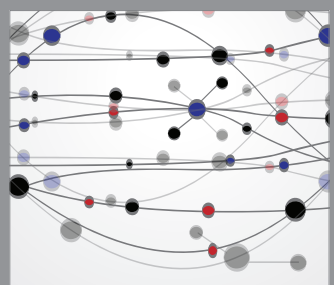

The Scientific World Journal
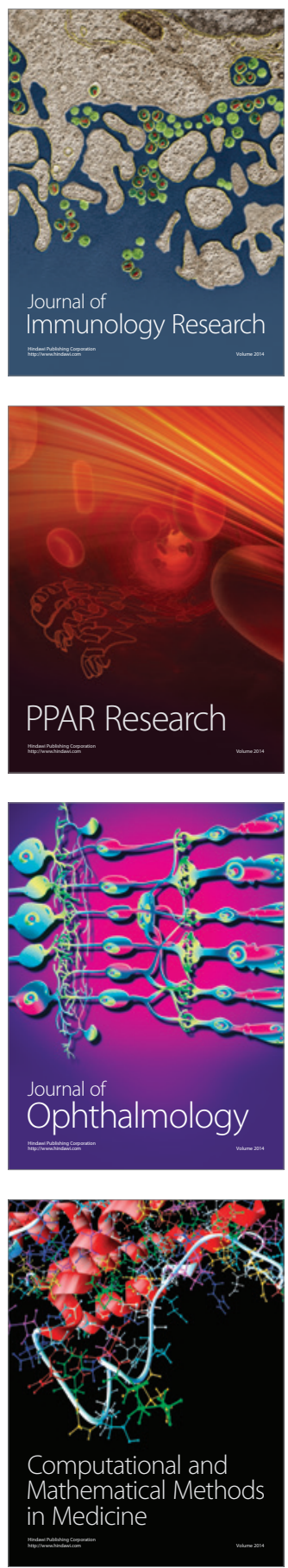

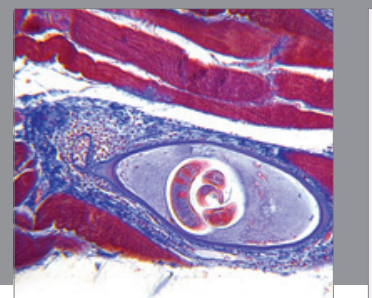

Gastroenterology

Research and Practice
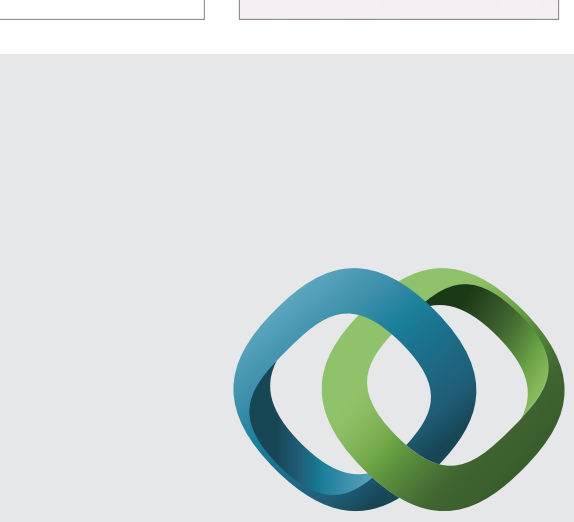

\section{Hindawi}

Submit your manuscripts at

http://www.hindawi.com
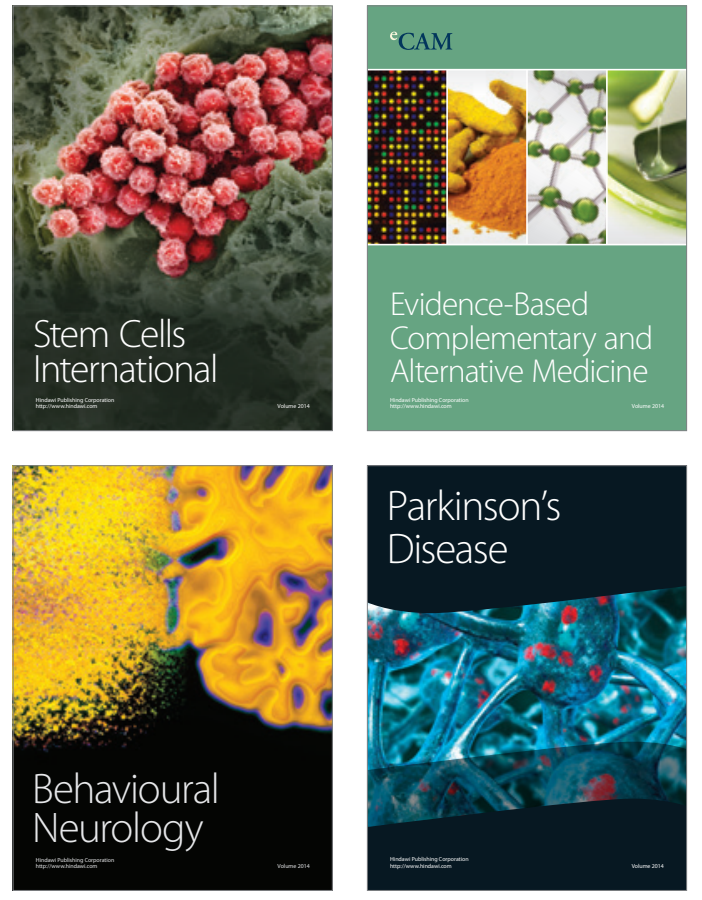
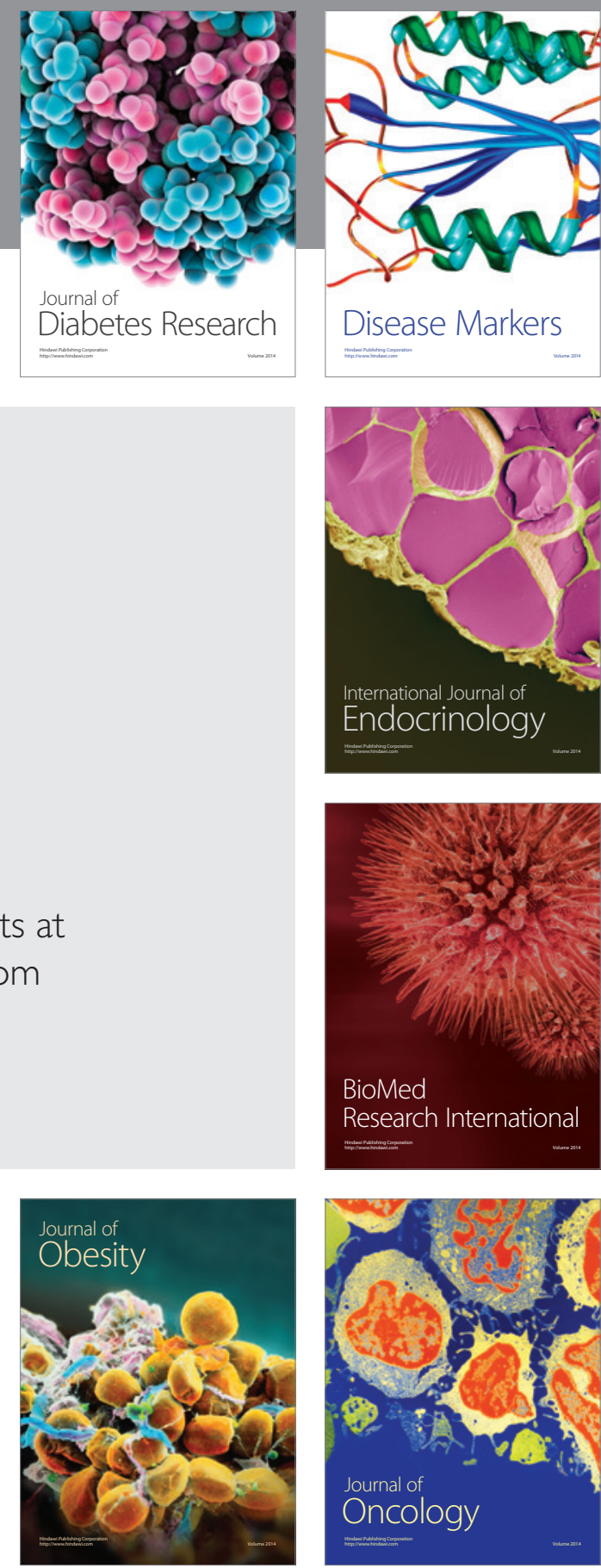

Disease Markers
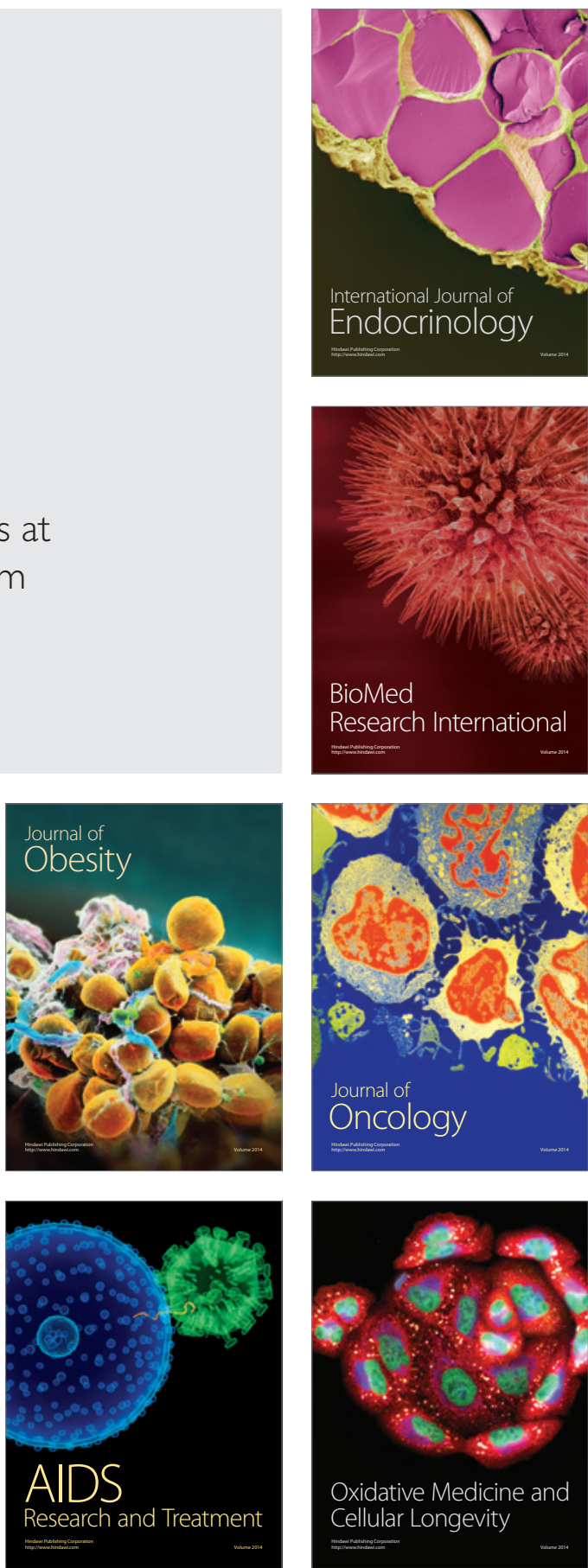